\title{
Preliminary explorations of the performance of a novel small scale opposed rotary piston engine
}

Jianbing Gao ${ }^{1, *}$, Guohong Tian ${ }^{1, *}$, Phil Jenner ${ }^{2}$, Max Burgess ${ }^{2}$, Simon Emhardt $^{1}$

1. Department of Mechanical Engineering Sciences, University of Surrey, GU2 7XH, UK

2. Enigma England Ltd, Kent, ME19 5NX, UK

Corresponding author:

Guohong Tian, g.tian@surrey.ac.uk

Department of Mechanical Engineering Sciences, University of Surrey, GU2 7XH, UK 


\begin{abstract}
With the increasing pressure of fossil fuel consumption and pollutions from vehicles powered by internal combustion engines, much attention has been attracted for hybrid and electric vehicles. With this background, an increasing demand for compact and high power density engines is being developed for the purpose of hybrid vehicles. In this paper, the design of a novel opposed rotary piston engine was investigated. In comparison with conventional reciprocating engines, this design has no crank connecting rods and intake/exhaust valves, and the operation cycle takes $360^{\circ}$ crank angle to complete but similar to a four stroke cycle. 3D and 1D simulations were conducted to analyse the in-cylinder flow and evaluate the engine performance. The simulation results indicated the air velocity was very high at the end of intake stroke due to the lack of intake valves. The opposed rotary piston engine had a higher fraction of constant volumetric combustion that yielded to less heat loss, which contributed to a higher power output per combustion cycle than a reciprocating engine at low engine speed. The estimated minimum brake specific fuel consumption and maximum power density were $240 \mathrm{~g} /(\mathrm{kW} \cdot \mathrm{h})$ and approximately $80 \mathrm{~kW} / \mathrm{L}$, respectively.
\end{abstract}

Keywords: opposed rotary piston; spark ignition engine; in-cylinder flow characteristics; charging efficiency; power output estimation

\title{
1. Introduction
}

With the global trend of reducing energy consumption and air pollutions, the automotive manufacturers devote to develop more efficient vehicles with lower emissions [1,2], with the aim to meet 2020 carbon dioxide $\left(\mathrm{CO}_{2}\right)$ emission targets [3]. Gao et al. [4] detailed analysed the energy flow of a turbocharged diesel engine. The results show that only 1\% 3\% (recycled by turbocharger from exhaust) of the fuel chemical energy, flowing into the cylinders eventually to increase the intake air density, is recycled by the turbocharger, although the waste energy in exhaust is more than $30 \%$ of the fuel chemical energy. Electric vehicles [5] and hybrid vehicles [6] have attracted much attention due to their cleaner operation and potentially higher efficiency. However, the battery energy density, charging durations, life span and infrastructures limit the market penetration of electric vehicles, despite the tremendous improvements achieved over these challenges [7]. Hybrid vehicles have been considered a more feasible solution for a larger range of vehicles due to their technological and economic advantages over electric vehicles. This gives opportunities to other forms of engines as a power source since the demands are different. For instance, a Wankel engine 
has smaller size, simpler structures and lower noise due to non-reciprocating mechanism and fewer moving parts [8]. Three power strokes in one shaft revolution result in a high power density, which effectively decreases the engine size and mass, thus making it a promising range extender for hybrid vehicles. Wankel engines also have multi-fuel capability [9] and can operate in either a direct injection mode [10] or a port fuel injection mode [11]. The effect of the synthetic fuels (bioethanol) on the performance and emissions of a Wankel engine was conducted by Siadkowska et al. [12]. The results showed that the brake specific fuel consumption (BSFC) and nitrogen oxides $\left(\mathrm{NO}_{x}\right)$ increased slightly at low engine load conditions, but $\mathrm{NO}_{x}$ emissions increased considerably at high load.

Wankel engine researches have slowed down because of its poor brake thermal efficiency [13] and high exhaust emissions [14] compared with reciprocating engines. This is mainly caused by the long and narrow combustion chambers, which lead to a huge specific surface area (surface area over volume). Huge specific surface area of cylinders leads to high hydrocarbon emissions, which are caused by serious quenching effects. The Wankel engine structure deems that the flame spreads faster in the leading direction than the trailing direction, which causes the burning gas to be quenched by the cooling cylinder wall when squish happens to the trailing side [15]. In addition, the brake thermal efficiency and exhaust emissions will be worse at cold start conditions. Direct fuel injection [16, 17], stratified charge [18], turbocharged intake systems [19] have been applied to enhance the Wankel engine performance. Alternative fuels [17], hydrogen-enriched gasoline [20], hydrogen-enriched ethanol [21], hydrogen-enriched natural gas [22] were used to improve the in-cylinder combustion process as well. Fan et al. [23] studied the joint effect of fuel injection timing and angle on fuel/air mixture formation and combustion of a direct injection (DI) natural gas Wankel engine based on 3D simulation. In the research, a small injection angle was suggested when the injection timing was at a early stage of intake stroke for the ideal fuel distribution. Amrouche et al. [21] indicated that the hydrogen-enriched fuel effectively improved the combustion characteristics due to the wide flammability [24, 25], small quenching distance [26], high diffusive and flame propagation velocities [27, 28], and broadened lean burn limitations [1, 29]. Su et al. [15] investigated the combustion and exhaust emission characteristics of a hydrogen-blended n-butanol port injection Wankel engine at part load and stoichiometric conditions. Combustion chamber temperature and brake thermal efficiency increased simultaneously after hydrogen addition (0 6.3\%). The brake thermal efficiency increased by approximately $4 \%$ (6.3\% hydrogen addition), 
carbon monoxide (CO) and hydrocarbon (HC) emissions decreased by $\sim 3500$ ppm and $\sim 2 \%$, respectively. However, the $\mathrm{NO}_{x}$ emission increased from $70 \mathrm{ppm}$ to $130 \mathrm{ppm}$, which was caused by a $50{ }^{\circ} \mathrm{C}$ peak temperature increase in the combustion chamber. In addition, severe wear cannot be avoided due to the distinct sealing structures [30].

In a Wankel engine, the movements of rotor is featured with eccentric design and a Reuleaux triangle. There are other similar designs using the rotary pistons to form combustion chambers, e.g. Yo-mobile engine in Russia [31]. This combustion chambers of this design were formed by the adjacent pistons and engine block without eccentric rotors therefore the combustion chambers were not as narrow. This rotary piston engines inherited Wankel engines' merits including the potentials of less wear and quenching effect. Other novel designs, such as Deng et al. [32] invented a twin-rotor piston engine, which had a high power density and no complex valve mechanism. The configurations and working principles of the rotary piston engine were analysed, additionally, the piston velocity and acceleration during movements were investigated. The theoretical engine power output increased with the engine piston number increasing. Chen et al. [33] proposed a cylinder-embedded piston engine, where the sealing approach of the reciprocating engines could be applied for; meanwhile, the thermodynamic process was further analysed using Matlab/Simulink software [31]. However, the engine structure should be further improved to allow a more flexible spark timing, which is essential to optimise the in-cylinder combustion process and reduce the emissions [34]. In addition, the engine power output and brake thermal efficiency at the entire operation range should be evaluated to highlight the power density, which was expected to be the most prominent advantage. Zhang et al. [35] researched an opposite axial piston engine which contained a charging cylinder and a power cylinder. The operation principle was similar to a steam engine. The axial piston engine could operate at high speed up to $1.0 \times 10^{4} \mathrm{r} / \mathrm{min}$, and it achieved an excellent overall performance. Liu et al. [36] proposed a novel rotary-type intake/exhaust system for a piston-type compressed air engine. The intake and exhaust systems were re-designed to make the valves open and close in a very short time. This rotary system overcame the leakage issue at high in-cylinder pressure, which reached 13 bar. Pan et al. [37] also investigated the effects of intake and exhaust valve timing on the performances of an rotary engine. The parameters were recommended to be $30^{\circ}$ crank angle $(\mathrm{CA}), 240^{\circ} \mathrm{CA}, 30^{\circ} \mathrm{CA}$, and $280^{\circ} \mathrm{CA}$ for intake advance angle, intake duration angle, exhaust advance angle, and exhaust duration angle, respectively. Similar design of a novel centric reciprocating engine (CRE) was reported [38]. This type of engine was 
featured with only two active parts in the engine combustion compartment without any mechanical valves, and had extremely low weight. The naturally aspirated 1.15 litre prototype delivered approximately $150 \mathrm{~kW}$ power output, which was equivalent to a 2.3 litre conventional reciprocating engine.

In this paper, a novel opposed rotary piston (ORP) engine operates in four stroke principle was explored. This type of engine is promising to achieve low carbon footprint, low noise, smooth power delivery, and multi-fuel capability, in theory, as well as higher thermal efficiency and lower exhaust emissions compared to Wankel engines. Its stable operation (no eccentric design and crank connecting rods) allows lower idle speed to decrease the fuel consumption compared to a reciprocating engine. The theoretical power density was doubled compared with a reciprocating engine of same displacement, due to the double frequency of the power stroke. The four stroke ORP engine featured with the functionality of $120^{\circ}$ geometric angle for each stroke in one shaft rotation $\left(360^{\circ} \mathrm{CA}\right)$, which conduced to increase the engine charge efficiency in a given shaft crank angle $\left(90^{\circ}\right.$ CA). Firstly, the principle of the ORP engine was analysed in details, also, the potential advantages of the engine were stated. Then, the 3D simulations were performed using FLUENT software to analyse the in-cylinder flow characteristics to form the foundations of the intake and exhaust structure optimisation. Further, a 1D ORP engine model was developed using Ricardo WAVE by which the in-cylinder combustion characteristics were analysed. The engine performances, such as BSFC, engine power output and efficiency, were evaluated.

\section{Configurations of the opposed rotary piston engine}

A Wankel engine is characterised with an eccentric design and a Reuleaux triangle, which lead to long and narrow combustion chambers. The combustion chamber of the ORP engine is in cylindrical shape, similar to a conventional reciprocating engine. This implies higher brake thermal efficiency and lower exhaust emissions compared to a Wankel engine. A simplified 3D engine model which only concerns the core combustion chambers and intake/exhaust is shown in Figure 1. The engine model used in this research includes two symmetric engine blocks, four pistons, two spark plugs and two shafts. Piston 1 and piston 3 are connected to shaft 1 as a whole, while piston 2, piston 4 and shaft 2 are connect as a whole. These two shaft are coaxial, and the shafts are fixed by the holes on the engine blocks, as shown in Figure 2. The angle between the centres of piston 1 and piston 3 is $180^{\circ}$, the same for piston 2 and piston 4 . The combustion chamber is composed of the end faces of two adjacent pistons, surfaces of two shafts and two blocks, as shown in Figure 1(d). 
The relative position of piston 1 and piston 2 need to be adjusted to ensure the exact movements. Combustion chamber volume variations will be shown in the following sections. In the future work, a mechanical structure will be introduced to convert the torque from the two shafts into one dominated shaft, which is connected to the flywheel as the power output. Three intake valves and one exhaust valve are included; in addition, two spark plugs are symmetrically positioned, with the shaft end surface as the symmetric plane. Four power strokes are finished when the shafts rotate $360^{\circ}$ CA, which indicates a higher theoretical power density than a reciprocating engine. The basic specifications of the ORP engine are listed in Table 1. The compression ratio of the ORP engine is at the same level of a naturally aspired gasoline engine.

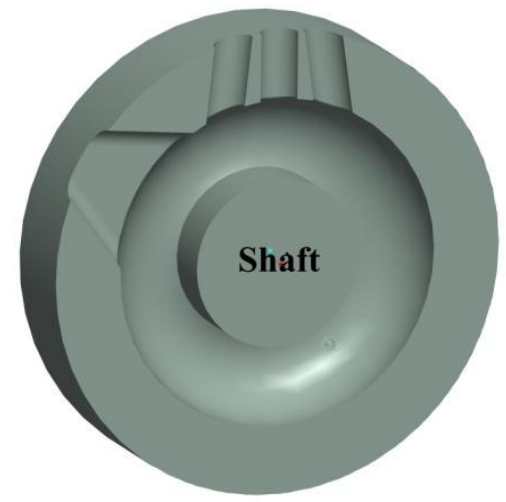

(a) Engine block

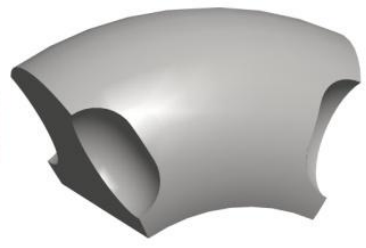

(b) Piston

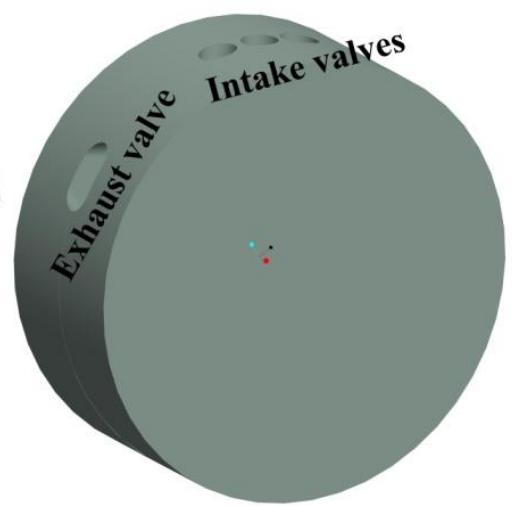

(c) Assembly

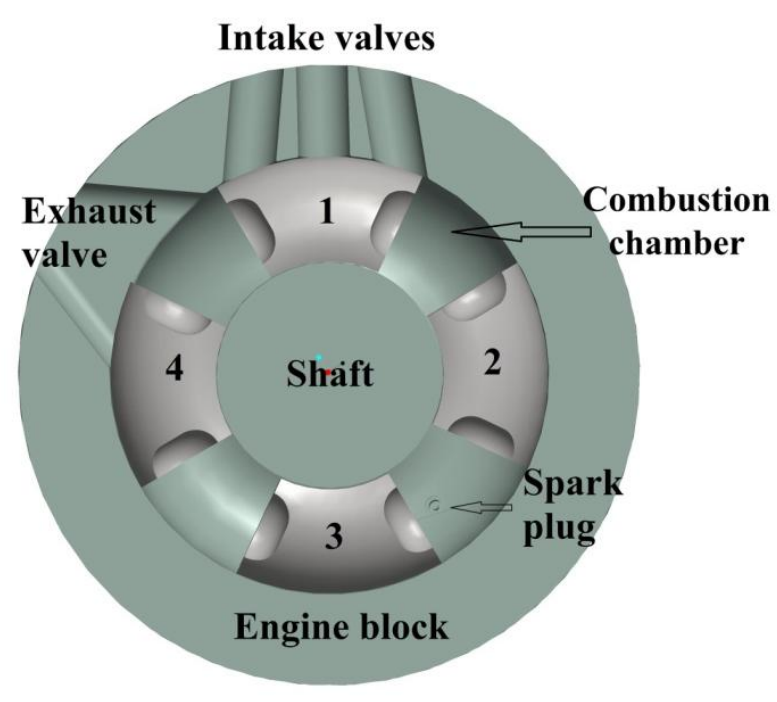

(d) Detached figure

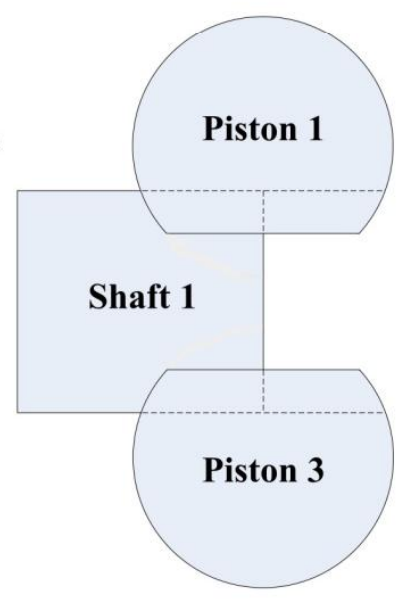

(e) Sketch of connectivity for pistons and shaft

Figure 1 The structure and assembly of the ORP engine model 


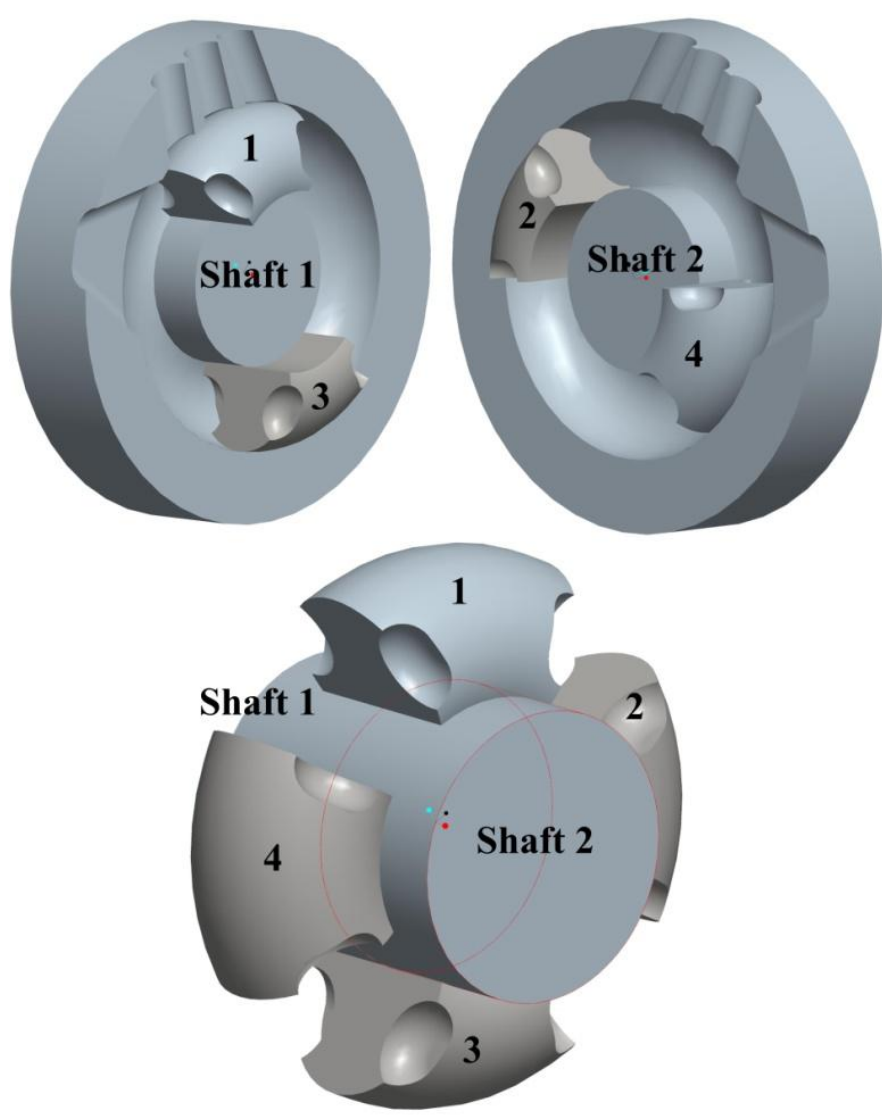

Figure 2 The approach of the connections between pistons and shaft

Table 1 Specifications of the ORP engine

\begin{tabular}{lc}
\hline Specification & Value \\
\hline Stroke number & 4 \\
Cylinder number & 4 \\
Displacement/ L & 0.5468 \\
Compression ratio & 9.73 \\
Intake system & Naturally aspirated \\
Fuel & Gasoline \\
Bore/ mm & 59.5 \\
Chord length of the piston/ mm & 59.0 \\
Geometric angle of the two end & 56 \\
surface in piston/ ${ }^{\circ}$ & \\
Intake valve number & 3 \\
Exhaust valve number & 2 \\
Spark plug number & \\
\hline
\end{tabular}


The end faces of the pistons contain two bowls, which enhance the turbulence intensity of the air/fuel mixture, also, widen the ranges of the spark timing. The sealing between the pistons and engine blocks is a challenge due to the bowls on the end faces, which may lead to higher unburnt fuel quenching in the crevice between the engine blocks and pistons. In addition, the design requires high accuracy because high tolerances could cause a slight eccentricity of shaft installation, which would lead to high vibration, noise and wear. The engine block surfaces, shaft surface, combined with the piston end faces (leading surface and trailing surface) and bowl surfaces of the two adjacent pistons, compose the combustion chambers. When the pistons are at the top dead centre (smallest cylinder volume), the angle between the two piston end faces is smaller than $3^{\circ}$ geometric angle, as shown in Figure 3, and the piston movements and rotation direction with the crank angles are shown in Figure 4. Top dead centre (TDC) is designated as the positions where the angle between the two adjacent piston end faces is the smallest (2 TDC positions, as shown in the first column of Figure 4). The optimal spark timing changes greatly with the engine speed and load [3, 39]. During the piston rotation, the bowls sweep through the location of the two spark plugs and it allows the spark timing to be changed. The double spark plugs design offers a more secured ignition and better reliability. The separation of the exhaust valve and the combustion chamber decreases the high temperature points during the combustion process, which reduces the possibility for knocking. In order to investigate the in-cylinder flow characteristics, the gravity centre movements of pistons 3 and 4 were measured, as indicated in Figure 3. These two gravity centre movements were converted into the phase difference of the two end faces of the cylinders (corresponding to the angles of the fluid domain). The maximum and minimum angles of the fluid domain in movement process were $65.23^{\circ}$ and $2.77^{\circ}$, respectively. The combustion chamber volumes as the function of the crank angle during the engine operation process will be further explored to analyse the in-cylinder combustion, brake thermal efficiency, and engine power output. 


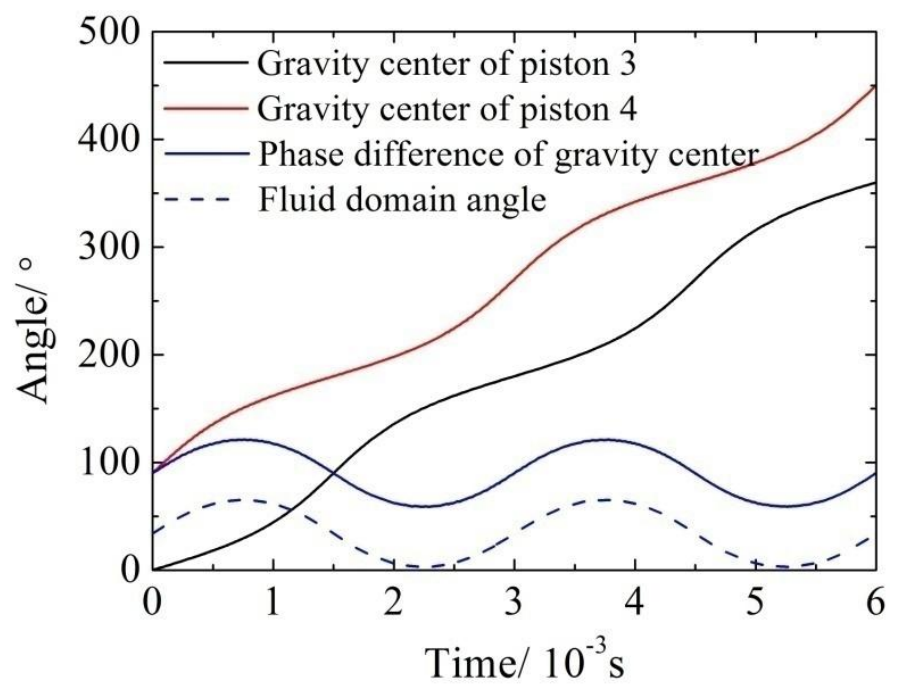

Figure 3 The piston gravity centre movement and phase changes of fluid domain between two adjacent pistons: $1000 \mathrm{rpm}$ 


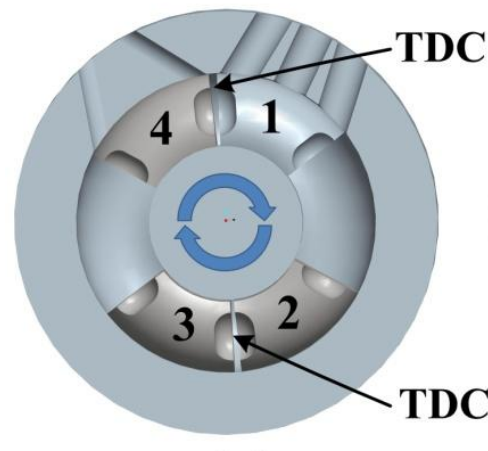

$0^{\circ}$
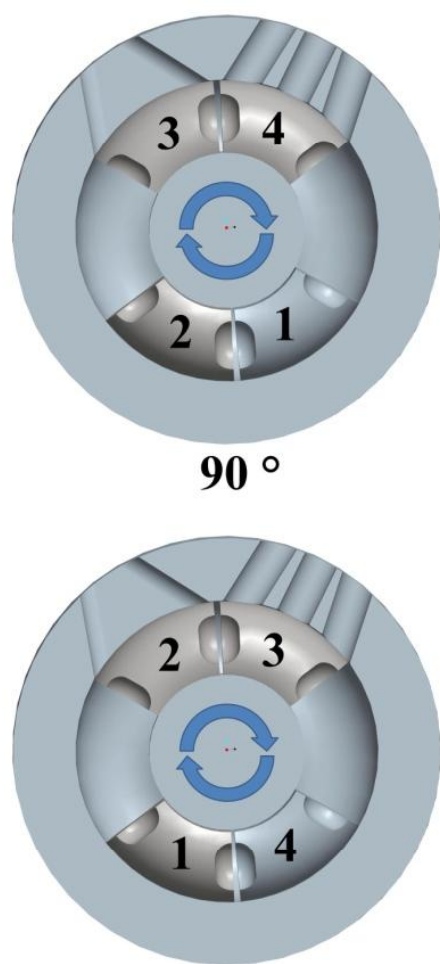

$180^{\circ}$

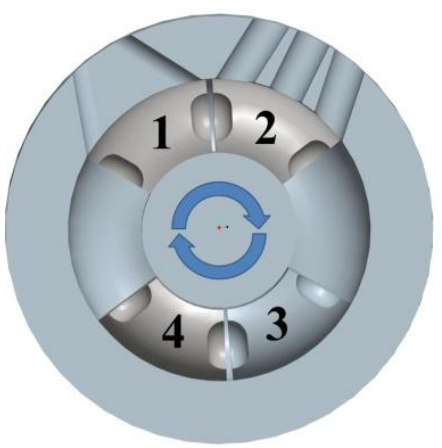

$270^{\circ}$

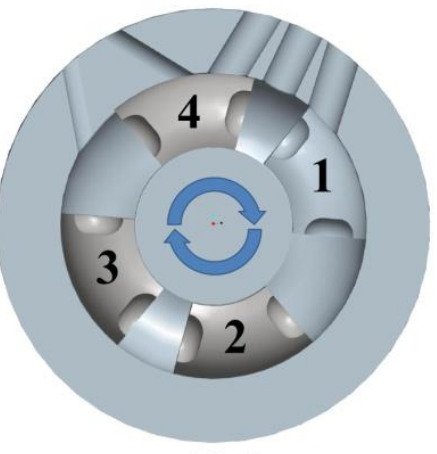

$30^{\circ}$

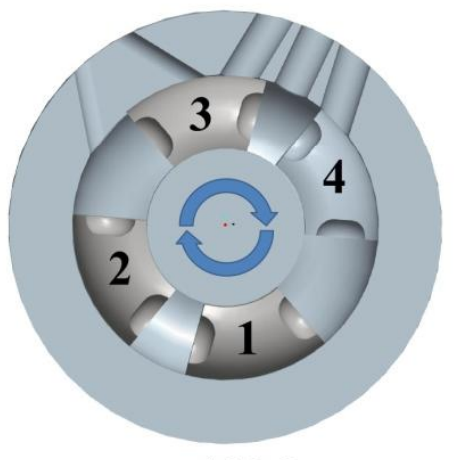

$120^{\circ}$

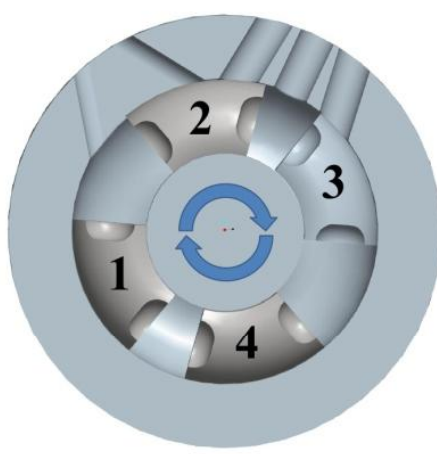

$210^{\circ}$

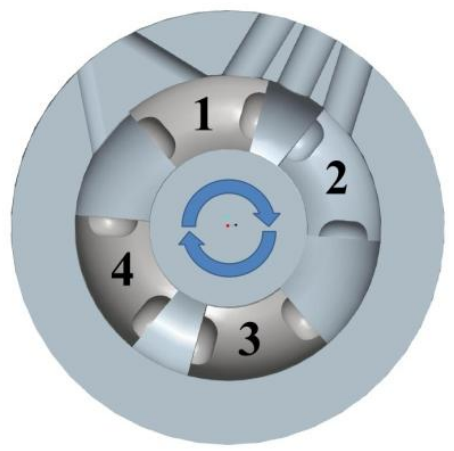

$300^{\circ}$

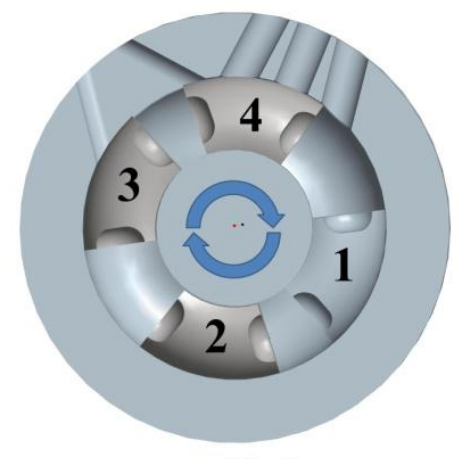

$60^{\circ}$

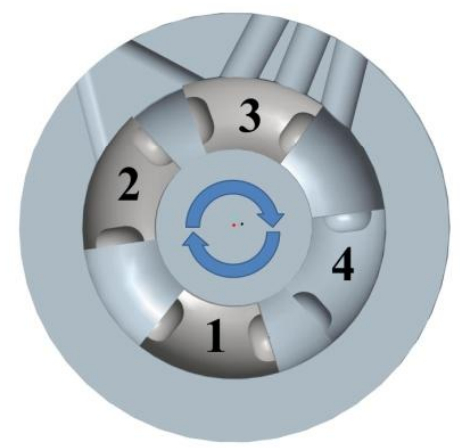

$150 \circ$

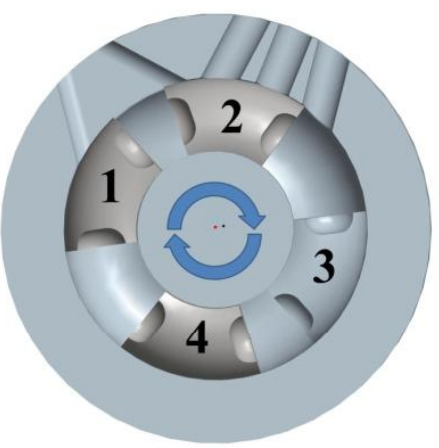

$240 \circ$

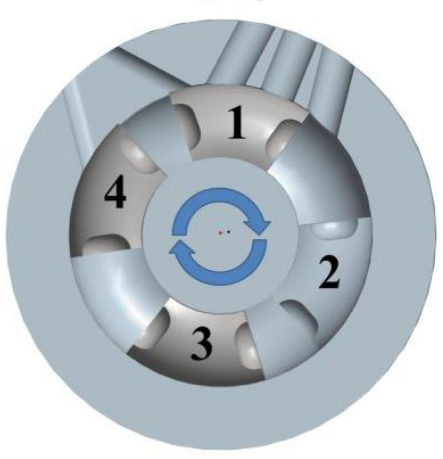

$330 \circ$

Figure 4 Piston movements with shaft rotation angles

\section{Numerical methodology}

Commercial software packages, ANSYS FLUENT and Ricardo WAVE, were employed to perform the unsteady numerical simulations and predict the engine performance, such as the engine power 
output and brake thermal efficiency. For the 3D simulations, the unsteady flow without combustion was analysed to form the foundations of the structure optimisation.

\subsection{D simulation theory}

The commercial code ANSYS FLUENT is based on the finite volume method. The Reynolds Averaged Naiver-Stoke (RANS) turbulence model is the standard $k$-epsilon model. The transport equations of $k$ and $\varepsilon$ are as Equations 1 and 2, and the details of the parameters were referred to the reference [40].

For the turbulent kinetic energy $k$

$\frac{\partial}{\partial t}(\rho k)+\frac{\partial}{\partial x_{i}}\left(\rho k u_{i}\right)=\frac{\partial}{\partial x_{j}}\left[\left(\mu+\frac{\mu_{t}}{\sigma_{k}}\right) \frac{\partial k}{\partial x_{j}}\right]+P_{k}+P_{b}-\rho \varepsilon-Y_{M}+S_{k}(1)$

For the dissipation $\varepsilon$

$\frac{\partial}{\partial t}(\rho \varepsilon)+\frac{\partial}{\partial x_{i}}\left(\rho \varepsilon u_{i}\right)=\frac{\partial}{\partial x_{j}}\left[\left(\mu+\frac{\mu_{t}}{\sigma_{\varepsilon}}\right) \frac{\partial \varepsilon}{\partial x_{j}}\right]+C_{1 \varepsilon} \frac{\varepsilon}{k}\left(P_{k}+C_{3 \varepsilon} P_{b}\right)-C_{2 \varepsilon} \rho \frac{\varepsilon^{2}}{k}+S_{\varepsilon}(2)$

$P_{k}$ represents the generation of turbulence kinetic energy due to the mean velocity gradients; $P_{b}$ represents the generation of turbulence kinetic energy due to buoyancy; $Y_{M}$ is the contribution of the fluctuating dilatation in the compressible turbulence to the overall dissipation rate [40]. $C_{1 \varepsilon}=$ $1.44, C_{2 \varepsilon}=1.92, C_{3 \varepsilon}=-0.33, \sigma_{k}=1, \sigma_{\varepsilon}=1.3$

The turbulent viscosity is defined as

$\mu_{t}=\rho C_{\mu} \frac{k^{2}}{\varepsilon}$

$P_{k}=-\overline{\rho u_{\imath}^{\prime} u_{j}^{\prime}} \frac{\partial u_{j}}{\partial x_{i}}$

$P_{k}=-u_{t} S^{2}$

Where, $C_{\mu}=0.09, \mathrm{~S}$ is the modulus of the mean rate-of-strain tensor, it was defined as

$S S \equiv \sqrt{2 S_{i j} S_{i j}}$

$P_{b} \equiv \beta g_{i} \frac{u_{t}}{P_{r_{t}}} \frac{\partial T}{\partial x_{i}}$

Where, $P_{r_{t}}$ is the turbulent Prandtl number for energy; $g_{i}$ is the component of the gravitational vector in the $i_{\text {th }}$ direction. For the standard and realisable-models, the default value of $P_{r_{t}}$ is 0.85 . The coefficient of thermal expansion, $\beta$, is formulated as

$\beta \equiv-\frac{1}{\rho}\left(\frac{\partial \rho}{\partial T}\right)_{p}$

The governing equation of computational fluid dynamics is defined as, 
$\frac{d}{d t} \int \rho \emptyset d V+\int \rho \emptyset\left(\vec{u}-\overrightarrow{u_{g}}\right) d \underset{A}{\rightarrow}=\int \Gamma \nabla \emptyset d \underset{A}{\rightarrow}+\int S_{\emptyset} d V$

Where, $d V$ is the boundary control volume; $\rho$ is the working fluid density; $\vec{u}$ and $\underset{u_{g}}{\text { are }}$ the flow velocity and the grid velocity of the moving mesh, respectively; $\Gamma$ is diffusion coefficient; $S_{\emptyset}$ is the source term [40].

\subsection{D computational grid}

In order to shorten the calculation duration and lower the workstation capacity requirement, only one combustion chamber fluid domain was included. Inevitable this assumption generates errors because a previous chamber will have effects on the next chamber and this scenario cannot be reflected by the model construction. However due to the limitations of computational resources and more importantly, the influence from the previous chamber is considered to be insignificant, the model was believed to be able to deliver fairly accurate prediction that can assist optimisation in early stage. Figure 5 shows the discretized computational domains of the ORP engine, which is composed of eleven sub-domains: three intake pipes, two spark plugs, one exhaust pipe, and one combustion chamber (four bowls and one cylinder). The hexahedral meshes were applied to all the sub-domains. Table 2 shows the grid numbers of the computational sub-domains, the total element number was 2710453 at the beginning of simulation. Since the combustion chamber volume changed greatly in the operation process, which led to the changes in the grid number. To ensure the mesh quality of the cylinder domain, a key technique of mesh processing, dynamic mesh was employed in the unsteady simulations. The cylinder mesh increased or decreased in layers during the piston movements. So that the divided meshing of the bowls and cylinder contributed to the proceeding of the dynamic mesh. Video S1 in the support information indicates how it works.

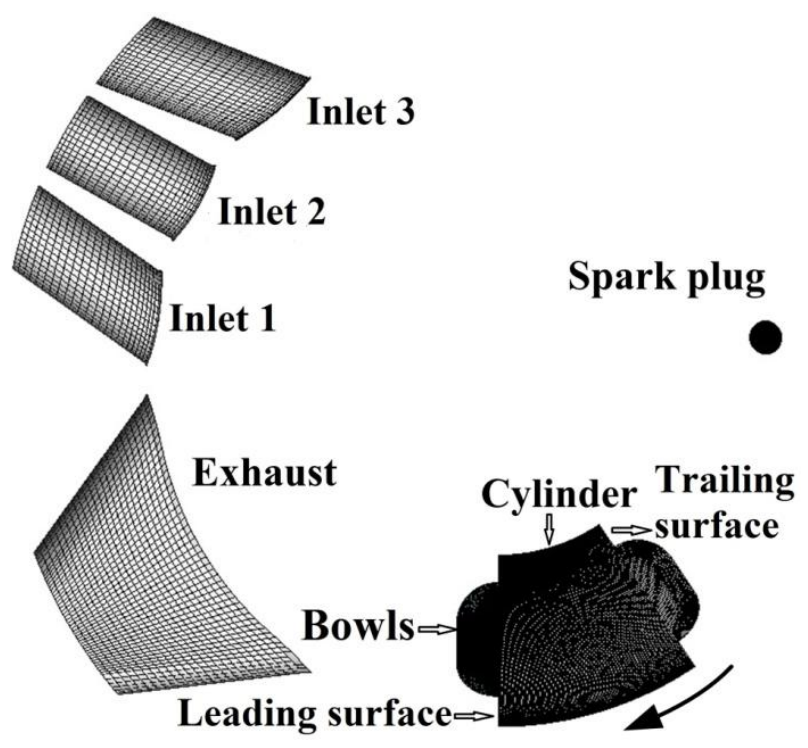


Figure 5 The discretised computational domains of the ORP engine

Table 2 Node and element numbers of the sub-domain grids

\begin{tabular}{lcc}
\hline Sub-domains & Nodes & Elements \\
\hline Intake valve 1 & 11300 & 12210 \\
Intake valve 2 & 11300 & 12210 \\
Intake valve 3 & 15425 & 16632 \\
Exhaust valve & 38025 & 40664 \\
Spark plug (each one) & 15452 & 18202 \\
Bowl (each one) & 105234 & 109845 \\
Cylinder (Initial stage) & 2113440 & 2152953 \\
\hline
\end{tabular}

\subsection{Stability and convergence of CFD calculation}

Table 3 shows the sensitivity test results of three different grid numbers. The boundary conditions of the simulation were kept the same for the three cases. They were set as: engine speed (1000 rpm); inlet pressure (1.0 bar); outlet pressure (1.0 bar); fluid (fresh air) and fluid temperature (293 K). The maximum deviations of the inlet mass flow rate, exhaust flow rate, and charging efficiency were $2.1 \%, 2.8 \%$ and $0.32 \%$, respectively, where the medium grid number case (2710453) was taken as the reference case. The grid independent solution was referred Wei's work [40]. Taking workstation calculation capacity and dynamic flow details (e.g. boundary layers) into consideration, the medium grid number (2710453) was used in the following work. The calculation was considered to be converged when the residuals of the velocity, energy, continuity, $k$ and epsilon were lower than $10^{-6}$.

Table 3 The simulation results among three different initial grid numbers (1000 rpm)

\begin{tabular}{lcccc}
\hline Grid number & Residuals & $\begin{array}{c}\text { Inlet mass flow } \\
\text { rate/ } \mathrm{kg} \cdot \mathrm{s}^{-1}\end{array}$ & $\begin{array}{c}\text { Exhaust flow rate/ } \\
\mathrm{kg} \cdot \mathrm{s}^{-1}\end{array}$ & $\begin{array}{c}\text { Charging } \\
\text { efficiency/\% }\end{array}$ \\
\hline 3893417 & $10^{-6}$ & $1.44 \times 10^{-2}$ & $1.45 \times 10^{-5}$ & 95.2 \\
2710453 & $5 \times 10^{-6}$ & $1.44 \times 10^{-2}$ & $1.42 \times 10^{-5}$ & 94.8 \\
& $10^{-6}$ & $1.43 \times 10^{-2}$ & $1.41 \times 10^{-5}$ & 94.9 \\
1542672 & $0.3 \times 10^{-6}$ & $1.43 \times 10^{-2}$ & $1.41 \times 10^{-5}$ & 94.9 \\
\hline
\end{tabular}

\subsection{Boundary conditions of 3D simulation}

The boundary conditions of the 3D simulation model are listed in Table 4 . The physical time step 
during simulation was $10^{-5} \mathrm{sec}(3000 \mathrm{rpm})$, which was decided by the rotation speed and minimum cylinder grid size. Since this work focused on the exploration of a novel ORP engine, experimental results were unavailable to validate the model.

Table 4 Boundary conditions for 3D simulations

\begin{tabular}{lc}
\hline Boundary conditions & Value \\
\hline Inlet pressure/ bar & 1.0 \\
Inlet temperature/ K & 293 \\
Outlet pressure/ bar & 1.0 \\
Cylinder wall temperature/ K & 293,573 \\
Rotation speed/ rpm & $1000,2000,3000,4000,5000,6000$ \\
Working fluid & Fresh air \\
\hline
\end{tabular}

\subsection{D simulation model description}

Ricardo WAVE was used to conduct the 1D simulations for the estimation of the engine power output, BSFC, and brake thermal efficiency. In the 1D simulation model, "DIWiebe" was used for the combustion sub-model, and "Woschini" sub-model was used for heat transfer. As for the friction losses, modified form of the "Chen-Flynn correlation" was applied that the constant part of friction mean effective pressure (FMEP, 0.3 bar), peak cylinder pressure factor, mean piston speed factor, mean piston speed squared factor, and engine speed upon entering friction transition band were used to calculated the friction loss. In order to establish the engine model, the cylinder shape and valve timing were simplified based on the 3D model. A fictitious cylinder having the same end surface size with the ORP engine was set up. The stroke was calculated using the end surface area and displacement. The geometric area changes of the intake and exhaust valves were obtained by measuring the overlapping area of the valves and working fluid during piston rotation. The geometric area changes of the intake and exhaust valves are shown in Figure 6. Each stroke lasts $120^{\circ}$ geometric angles theoretically although the centre of the combustion chamber rotated $90^{\circ} \mathrm{CA}$, which significantly contributed to the increase of the charging efficiency. However, this structure cannot be realised using commercial software WAVE. For the WAVE engine model whose combustion cycle period was $360^{\circ} \mathrm{CA}\left(90^{\circ} \mathrm{CA}\right.$ for each stroke, modified from a two stroke internal combustion engine model), such a late intake valve closing and early exhaust valve opening caused backflow and under-expansion in the intake and power strokes, respectively. In order to decrease 
the errors of the charging efficiency in the WAVE model, variable valve timing (VVT) was used in the $1 \mathrm{D}$ engine model, where the exhaust valve opening and intake valve closing timing were adjustable. The opening durations of the exhaust and intake valves were narrowed at low engine speed conditions, nevertheless, they were still greater than $90^{\circ}$ geometric angles.

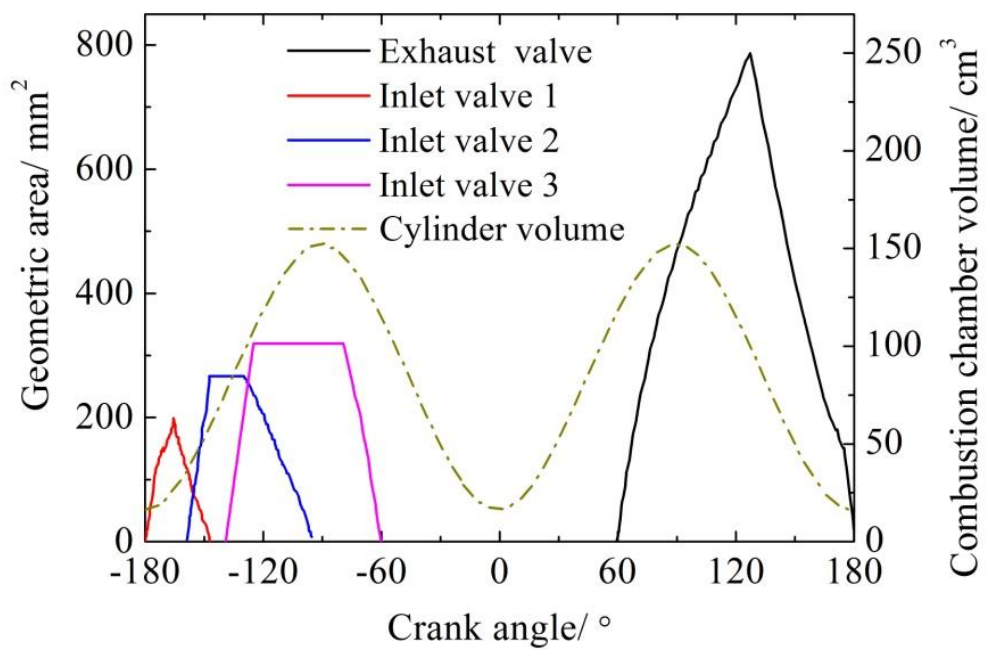

Figure 6 Geometric area changes of the intake and exhaust valve opening calculated based on 3D model

\section{Results and discussion}

Similar engines have been reported by Chen et al. [33] and Zhang et al.[35] from the point of the engine structures, and the piston movements were analysed based on the mathematical equations. To the authors' knowledge, the in-cylinder flow and performance estimations were not reported. The exhaust emissions, being important factors to evaluate the engine performance and the practical use, would be analysed in future works.

\subsection{D simulation results}

In the engine operation process, the in-cylinder flow significantly influences the charging efficiency [41], which dominates the engine power output of spark ignition (SI) engines. The analysis of the in-cylinder flow forms the foundations of improving the charging efficiency. An engine speed of $5000 \mathrm{rpm}$ was taken as an example to illustrate the ORP engine operation and analyse the in-cylinder flow. Figures 7 and Figure S1 show the 2D streamlines and pressure changes in the engine model's symmetric plane, respectively. The positions of the two cylinder end faces rotated with time, which was different from the reciprocating engines. In order to define the fluid domain (combustion chamber) positions, the symmetric planes of the two end faces were considered to be rigidly coupled with an imaginary shaft. The position, where the angle between the two piston end faces is the smallest, was TDC $\left(0^{\circ} \mathrm{CA}\right.$ and $\left.180^{\circ} \mathrm{CA}\right)$. Before the exhaust valve opening, double 
vortexes with inverse orientations were observed in the exhaust pipes although the vortex intensity was weak (velocity lower than $15 \mathrm{~m} / \mathrm{s}$ ). This was caused by the inertia of the working fluid. The vortexes were also observed in the inlet pipes, nevertheless, no strong turbulence existed in the combustion chamber. At the beginning of the exhaust stroke, backflow happened, which was caused by the low charging efficiency in previous cycle and heat loss during compression stroke. This could be identified from the in-cylinder pressure at $-97^{\circ} \mathrm{CA}$, where the combustion chamber pressure (lower than 0.9 bar) was slightly lower than the exhaust pipe. In the compression and beginning of power strokes, the combustion chamber temperature was higher than the wall temperature, especially at the end of compression stroke. The heat loss partly caused the low pressure at the end of power stroke. 


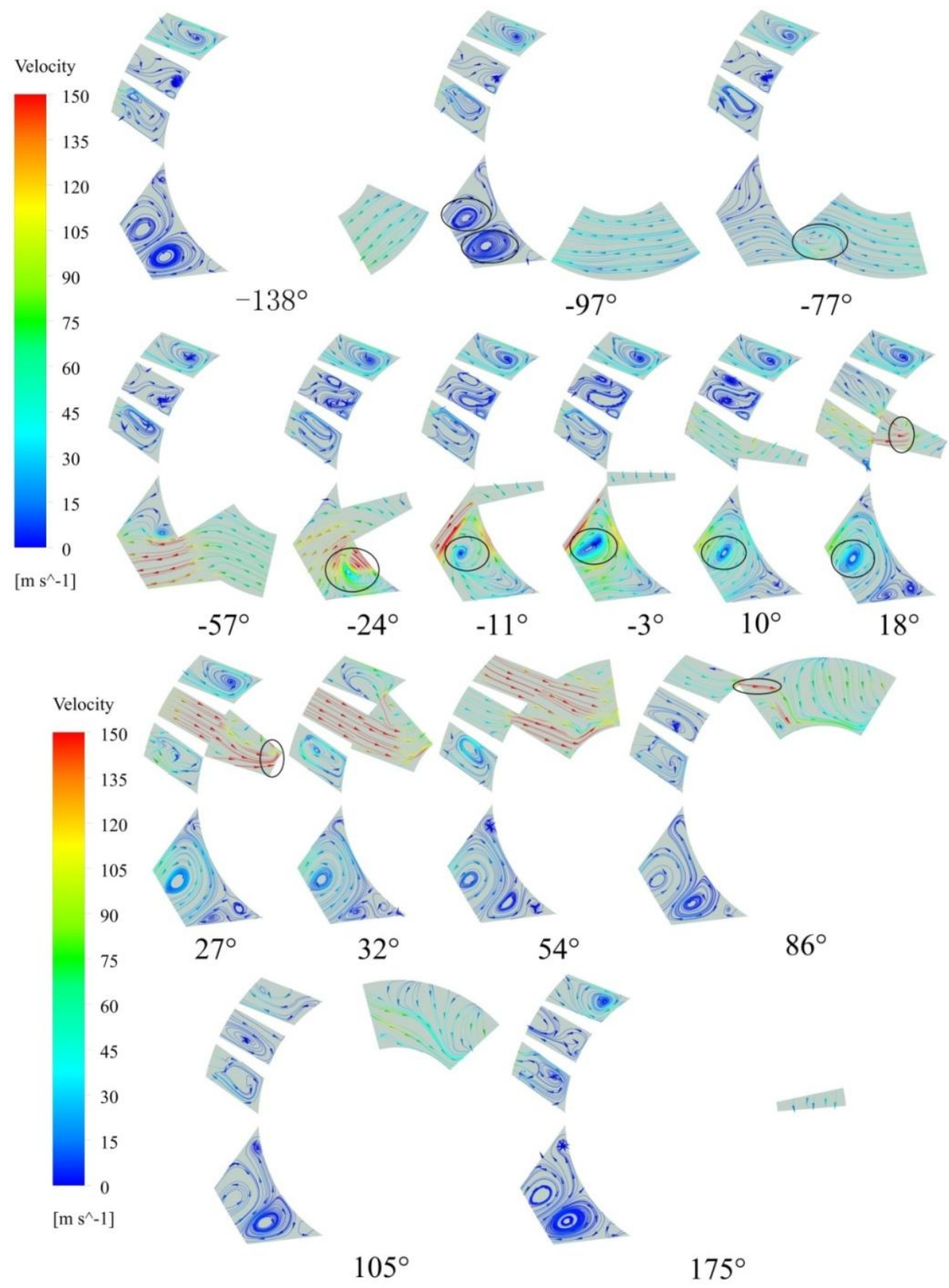

Figure 7 Streamline projection on the symmetry plane: $5000 \mathrm{rpm}$

With the piston rotating, angular velocity increase of the trailing face caused the high fluid velocity in exhaust pipe. Meanwhile, a high pressure zone was developed in a short time in the cylinder. The fluid velocity was higher than $150 \mathrm{~m} / \mathrm{s}$ at $-57^{\circ} \mathrm{CA}$, where the cylinder pressure was the highest in the exhaust stroke ( 1.5 bar); in addition, a high intensity vortex was formed in the exhaust pipe after the combustion chamber passed. The vortex also followed the movements of the combustion chamber, and gradually became weaker. The low pressure zones in the exhaust pipe moved following the vortex. It was evident that there was not overlap for the intake valves and the exhaust valve, which hindered the scavenging actions. The valve overlapping contributed to the decrease of 
the residual gas fraction and the increase of the charging efficiency [42]; thus the increase of the engine power output. However, the overlap may lead to escape of the fresh air/fuel mixture, thus increasing the exhaust emissions and fuel consumption. This phenomenon was evident for the two stroke spark ignition engines [43]. Since this ORP engine is aimed to be used as range extenders for electric vehicles, it will likely operate at high load conditions in order to achieve high thermal efficiency. As a result, the exhaust temperature and $\mathrm{NO}_{x}$ emissions are expected to be relatively high. This valve structure will allow internal exhaust gas recirculation (EGR) to decrease $\mathrm{NO}_{x}$ emissions; in addition, it may be beneficial to apply homogeneous charge compression ignition (HCCI) combustion, and super high pressure ratio turbocharger system, where a small or negative valve overlapping is needed. In fact, the exhaust stroke lasts $120^{\circ}$ geometric angle and it was considered a remarkable advantage for the ORP engines. This was a novelty in the structural design that it achieved $120^{\circ}$ geometric angle for each stroke in one cycle. In order to decrease the residual gas fraction, exhaust pipe should be re-structured to achieve a slightly early exhaust valve opening.

At the beginning of the intake stroke, the fresh air velocity was lower than $30 \mathrm{~m} / \mathrm{s}$. Negative pressure was not formed at this position since the angular speeds $(<30 \mathrm{rad} / \mathrm{s})$ of the two pistons are almost the same. With the piston rotating, the fresh air velocity was higher than $130 \mathrm{~m} / \mathrm{s}$ at the second intake valve position, which was caused by a large negative in-cylinder pressure $(\sim 0.6$ bar in Figure S1). Meanwhile, the airflow collisions from different valves strengthened the turbulence, which will contribute to increasing the flame propagation velocity at later stage, further, to enhance the brake thermal efficiency. The fresh air directly washed against the bottom surface of the combustion chamber, which also strengthened the air flow. However, it may result in gasoline condensing on the combustion chamber wall at cold start conditions. At the end of the intake stroke, the inlet flow velocity was still higher than $120 \mathrm{~m} / \mathrm{s}$ as a result of the fluid inertia. Similar to the exhaust stroke, the intake valve should be closed a little late to achieve higher charging efficiency. It should be noted that the late intake valve closing angle should be smaller than the reciprocating engines due to its smaller crank angle for each stroke. After the exhaust and intake strokes, the compression and power strokes continued.

Figure 8 shows the 3D streamlines at different positions, the viewing angles were adjusted to make the streamlines clear. In the exhaust process, air flowing out of the combustion chamber was dominated by the air from the cylinder and the two trailing bowls. This action led to much residual in the leading bowls, which may cause lower engine power output. The leading bowls should be 
downsized to decrease the residual gas fraction. In the intake process, when the third intake valve opened, the air flow direction was towards the two leading bowls, which made the residual gas dispersing in the whole combustion chamber.

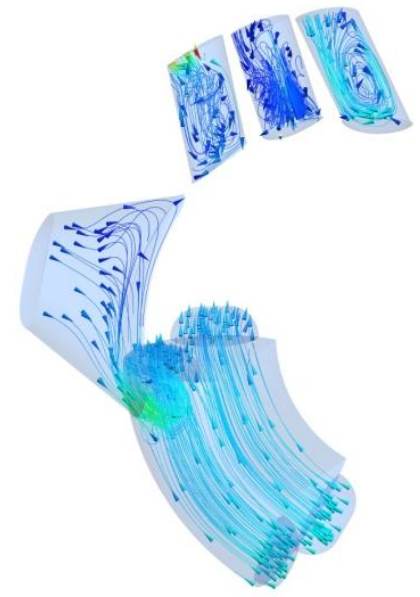

$-77^{\circ}$

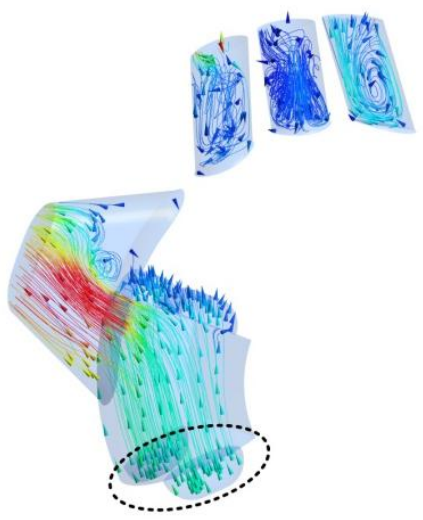

$-57^{\circ}$

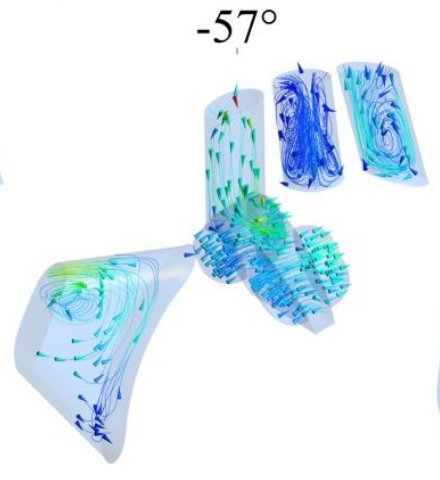

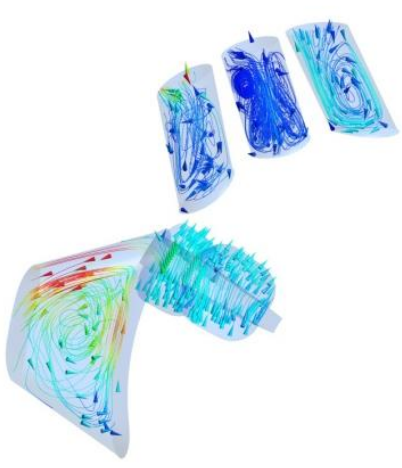

$-11^{\circ}$

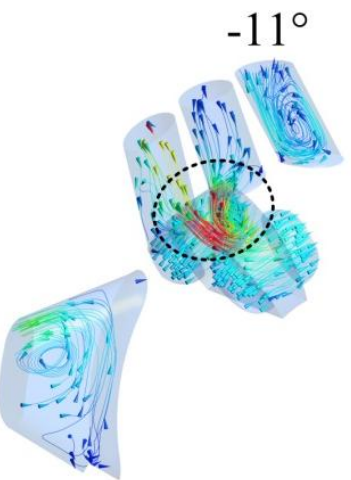

$18^{\circ}$

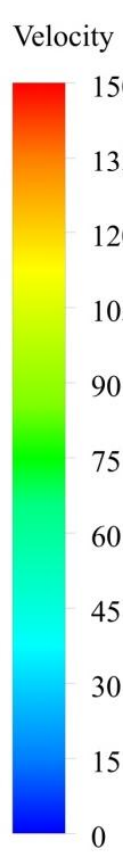

$\left[\mathrm{m} \mathrm{s}^{\wedge}-1\right]$

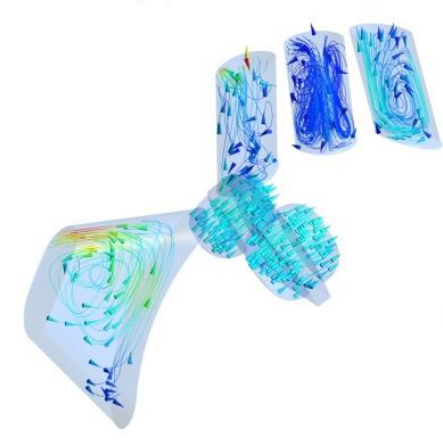

$4^{\circ}$

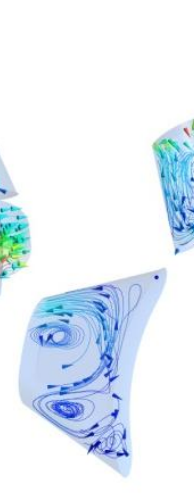

$32^{\circ}$ $10^{\circ}$

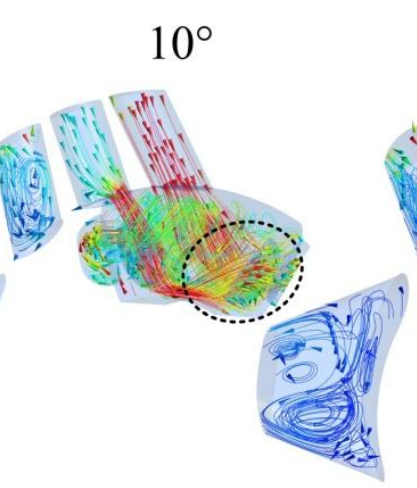

$54^{\circ}$

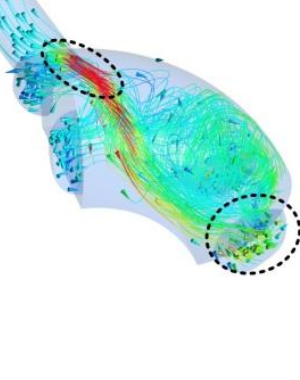

$86^{\circ}$

Figure 8 3D streamlines in the fluid domain: $5000 \mathrm{rpm}$

Higher engine speed means stronger air flow and less time for the intake process; additionally, the two factors have an inverse effect on the charging efficiency [44]. Figure 9 shows 2D streamlines at different engine speeds. For $-77^{\circ} \mathrm{CA}$ position, strong turbulences were formed in the combustion chamber when the exhaust valve was opened; also, a small vortex was formed in the exhaust pipe at $1000 \mathrm{rpm}$ condition. The turbulences in the combustion chamber were weaker at $2000 \mathrm{rpm}$ and $3000 \mathrm{rpm}$ engine speed. For the $4000 \mathrm{rpm}$ condition, almost no fluid flowed out from the 
combustion chamber, with large vortexes on both sides of the exhaust valve. The backflow can still be observed at $5000 \mathrm{rpm}$ because of low charging efficiency caused by high engine speed and heat loss during rotation. High engine speed also led to more residual gas in the combustion chamber. Due to the strong air flow, the velocity was approximately $100 \mathrm{~m} / \mathrm{s}$ at the end of the first inlet valve at high engine speed conditions (no less than $300 \mathrm{rpm}$ ). It was much obvious for $5000 \mathrm{rpm}$, that the fluid velocity was higher than $150 \mathrm{~m} / \mathrm{s}$ at the end of the intake stroke, which could have more fresh charge flowing into the combustion chamber if the valve closes later. Variable valve timing should be applied to the intake and exhaust valves to achieve a higher power density.

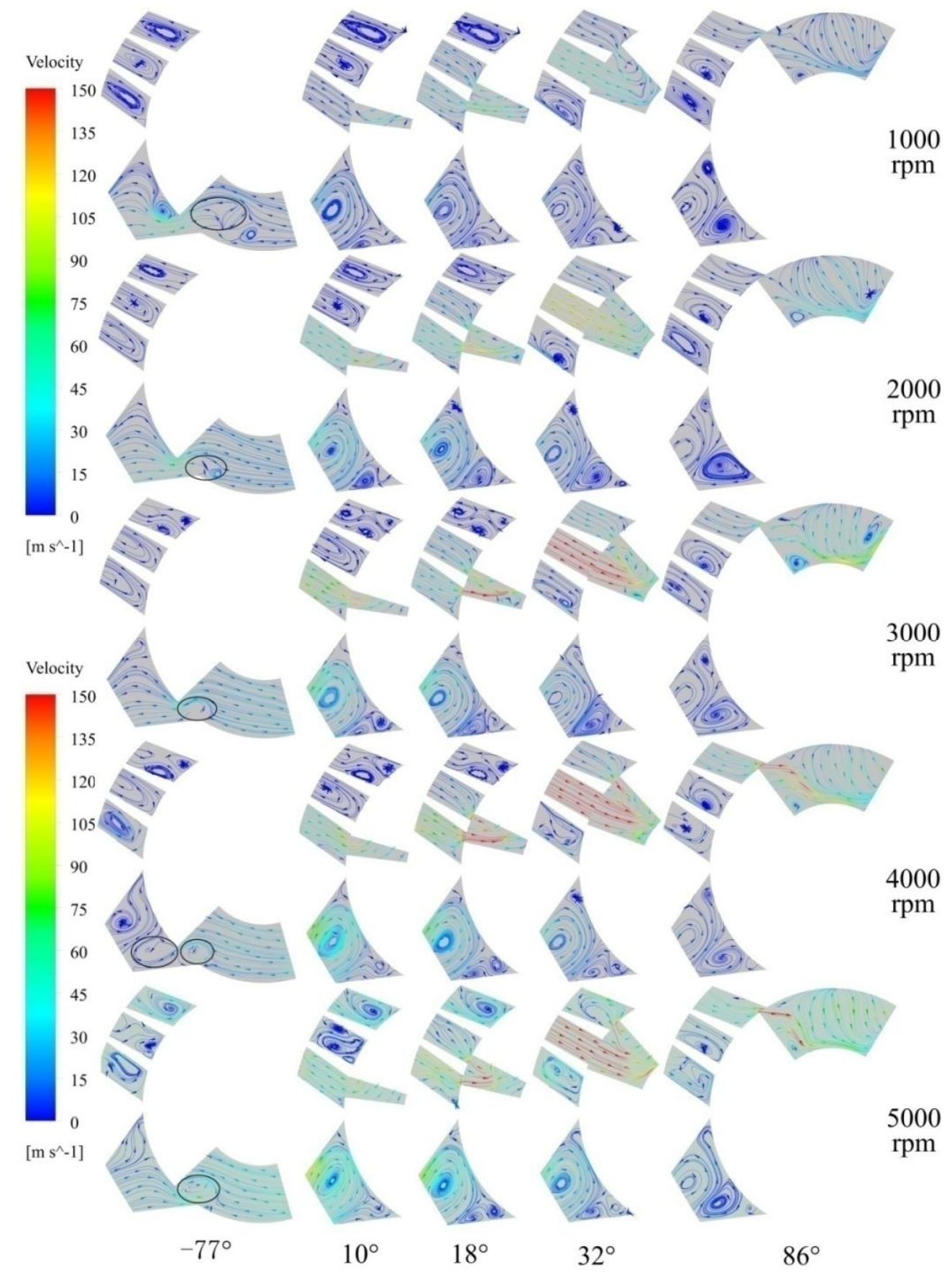

Figure 9 Comparison of streamline projection under different engine speeds 


\subsection{Theoretical analysis of ORP engine merits}

In order to preliminary evaluate the engine performance, especially the engine power density which was the most attractive advantage compared with the reciprocating engines, 1D simulation using Ricardo WAVE was conducted. Figure 10 shows the combustion chamber volume changes as a function of crank angle. Compared with the four stroke reciprocating engines, the slope of the profile was less sharp around TDC for the ORP engine, which meant a higher percentage of constant volumetric combustion, further, a higher theoretical brake thermal efficiency could be achieved. Additionally, shorter combustion time conduced to decrease the knock possibility [45] so that the compression ratio could be increased to improve the brake thermal efficiency. However, shorter time would lead to less post oxidation that more unburned hydrocarbon may be emitted. Similar to the Wankel engines, hydrogen addition could be used to increase the flame propagation velocity for decreasing the exhaust emissions and increase fuel economy [22, 46].

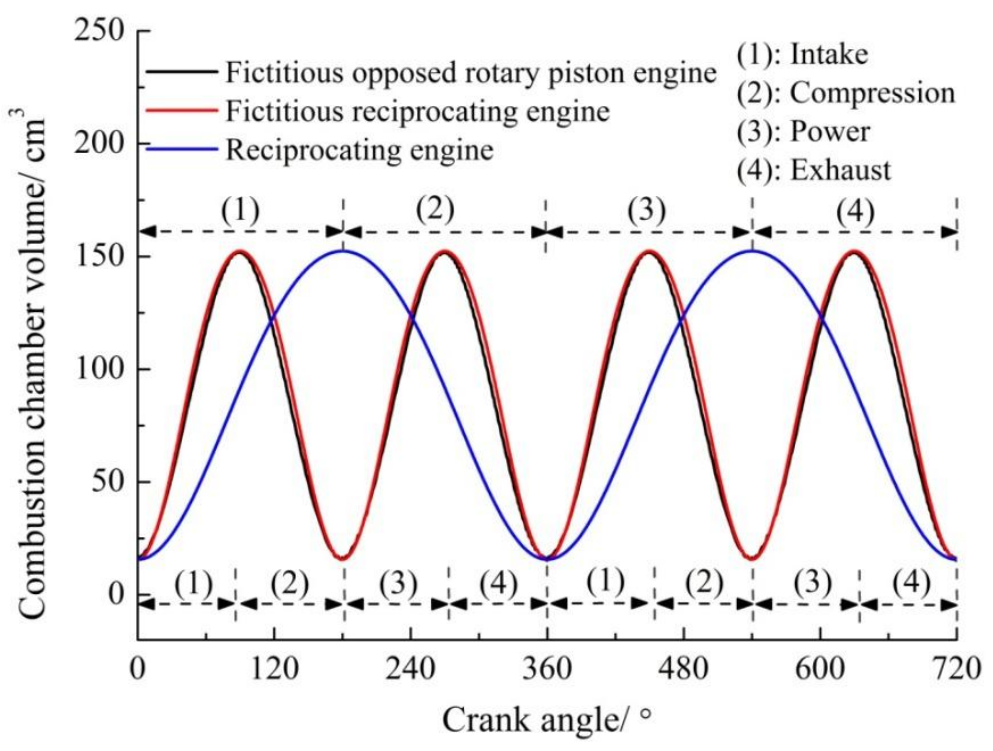

(a) Reciprocating engine and fictitious ORP engine 


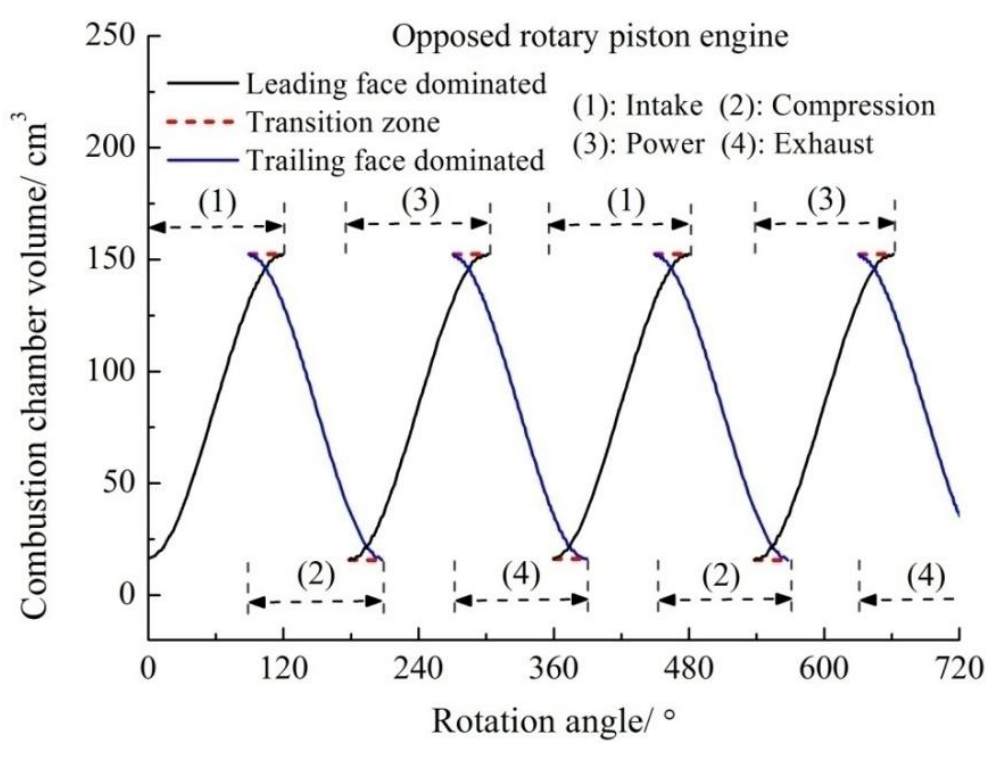

(b) ORP engine

Figure 10 Combustion chamber volume comparisons of reciprocating and ORP engines

The geometric angles that the cylinder leading surface passed were $60^{\circ}, 120^{\circ}, 60^{\circ}$ and $120^{\circ}$ in the exhaust stroke, intake stroke, compression stroke and power stroke, respectively; however, they were $120^{\circ}, 60^{\circ}, 120^{\circ}$ and $60^{\circ}$ for the trailing surface, as shown in Figure 11. As shown in Figure 7 and Figure S1, the leading surface dominated the geometric angle changes of the cylinder fluid domain in the intake and power strokes; and the trailing surface dominated for the compression and exhaust strokes. This phenomenon created the merit that each stroke lasting $120^{\circ}$ geometric angle in one shaft cycle.

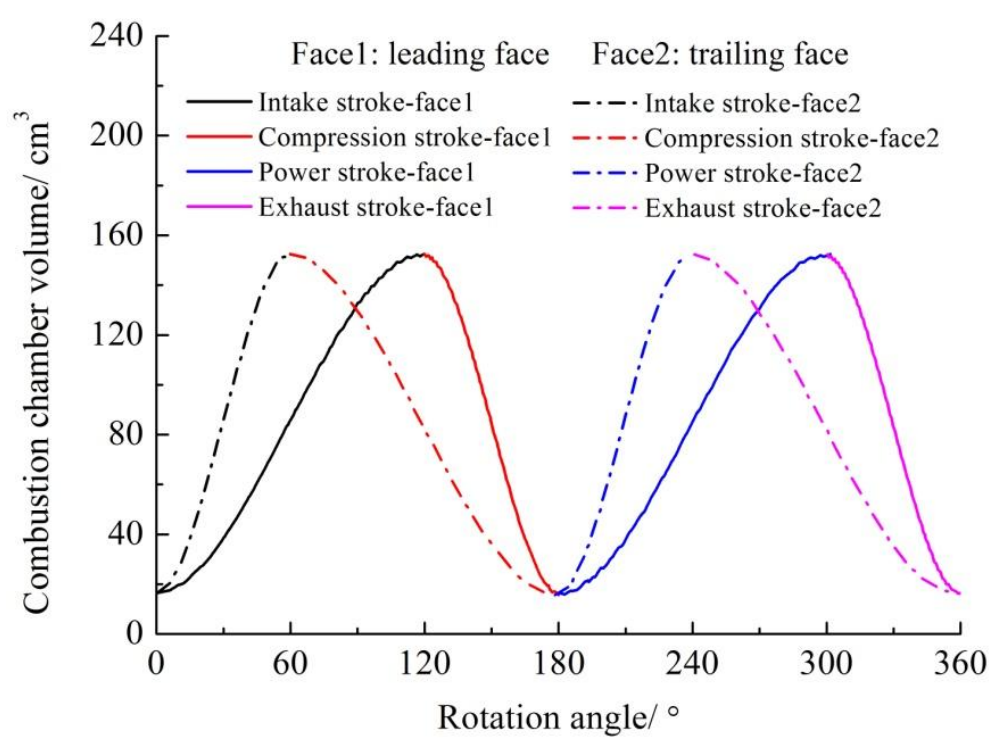

Figure 11 Combustion chamber volume from the perspective of leading and trailing faces

\subsection{ORP engine charging efficiency}

In order to evaluate the engine power output, the charging efficiency was analysed. The charging 
efficiency calculated using FLUENT and WAVE is shown in Figure 12. Two inlet structures were investigated in the WAVE model. The first structure was that the three inlet valves were independent, which was comparable with the 3D simulation model. The second structure was that the three intake pipes were joint to connect with the air filter. Charging efficiency was higher than $100 \%$ at some points, which was caused by the fluid inertia and pressure waves. It decreased greatly after engine speed exceeded $4000 \mathrm{rpm}$, where intake stroke experienced less time. The temperature of the combustion chamber wall in the 3-D model (cold cylinder) was $293 \mathrm{~K}$, the same temperature was set in the WAVE model based on intake structure 1. The charging efficiency calculated using WAVE model matched well with the FLUENT results; the difference was mainly caused by the simplified intake and exhaust valve timing.

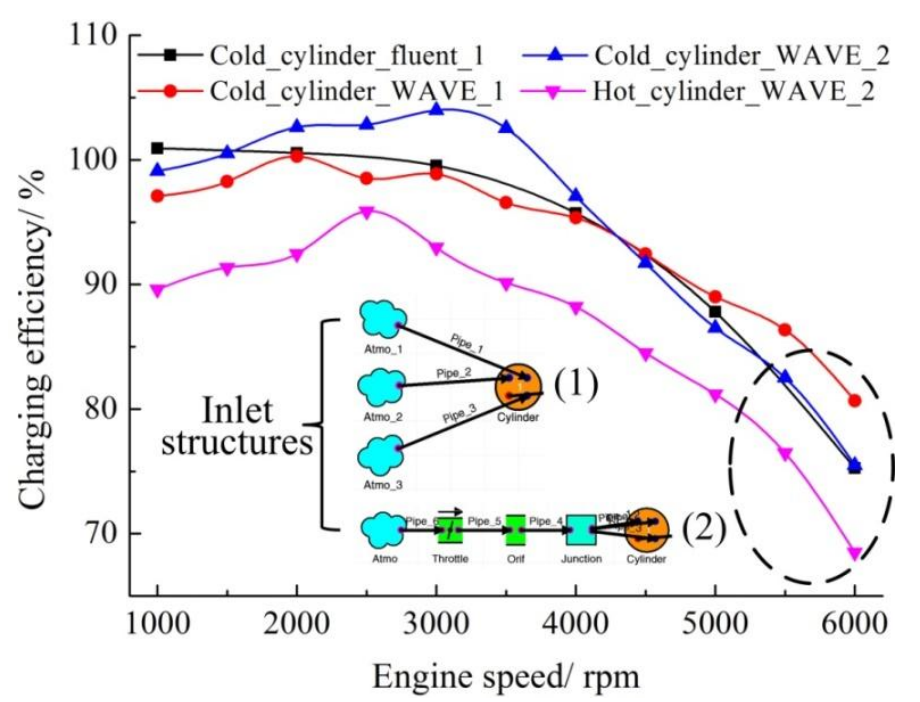

Figure 12 Charging efficiency calculated using FLUENT and WAVE under different engine speeds In real cases, the three intake pipes in the engines will be jointed to connect to an air filter, as presented in the structure 2 of Figure 12. The air flow in the intake pipes had interactive effects (pressure wave) in this case [47]. The effect enhanced the air flow, especially at medium engine speeds where the charging efficiency increased significantly. During engine normal operations, the cylinder wall temperature was high, which caused the decrease of charging efficiency. The maximum charging efficiency was approximately 95\%, while it was lower than $80 \%$ when the engine speed was higher than $5000 \mathrm{rpm}$ under the conditions of hot cylinder wall. Table 5 lists the charging efficiency calculated using FLUENT under the conditions of high wall temperature (573 $\mathrm{K})$. The difference of the calculated charging efficiency between FLUENT and WAVE was less than $2 \%$. For high engine speed conditions, a larger early exhaust valve opening and late intake valve closing [48] should be applied to compensate the charging efficiency decrease caused by the short 
stroke duration.

Table 5 Charging efficiency calculated using FLUENT under hot cylinder wall condition

\begin{tabular}{cccc}
\hline Rotation speed/ rpm & 1000 & 3000 & 6000 \\
\hline Charging efficiency & $87.5 \%$ & $90.6 \%$ & $70.1 \%$ \\
\hline
\end{tabular}

\subsection{ORP engine performance evaluation}

Figure 13 shows the effective valve opening area and cylinder pressure as a function of crank angle, under $1000 \mathrm{rpm}$ and $5000 \mathrm{rpm}$ conditions respectively. The peak pressure was approximately 50 bar at $1000 \mathrm{rpm}$, and it was slightly lower at $5000 \mathrm{rpm}$, which was caused by low charging efficiency. The cylinder pressure in the intake stroke at $5000 \mathrm{rpm}$ was evidently lower than $1000 \mathrm{rpm}$. Negative pressure was formed in a shorter time at $5000 \mathrm{rpm}$ so that the fresh air did not flow into the cylinder rapidly. Around $-160^{\circ} \mathrm{CA}$, the effective area decreased sharply which was caused by the air flow transferring from the first valve to the second one. The area decrease should be avoided by optimising the first two intake valve positions.

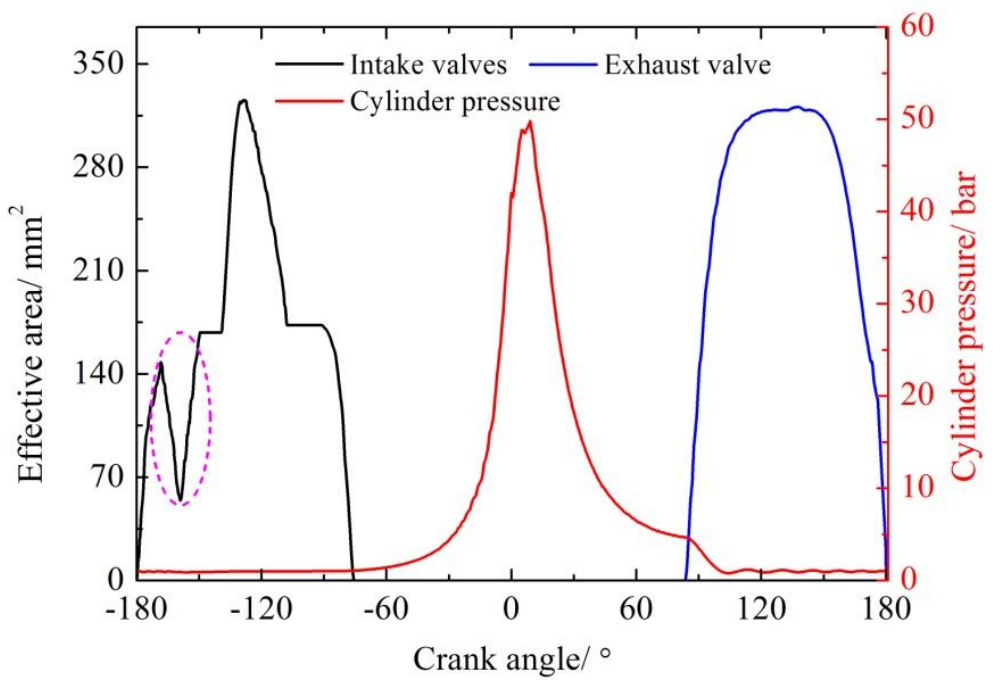

(a) $1000 \mathrm{rpm}, 100 \%$ load 


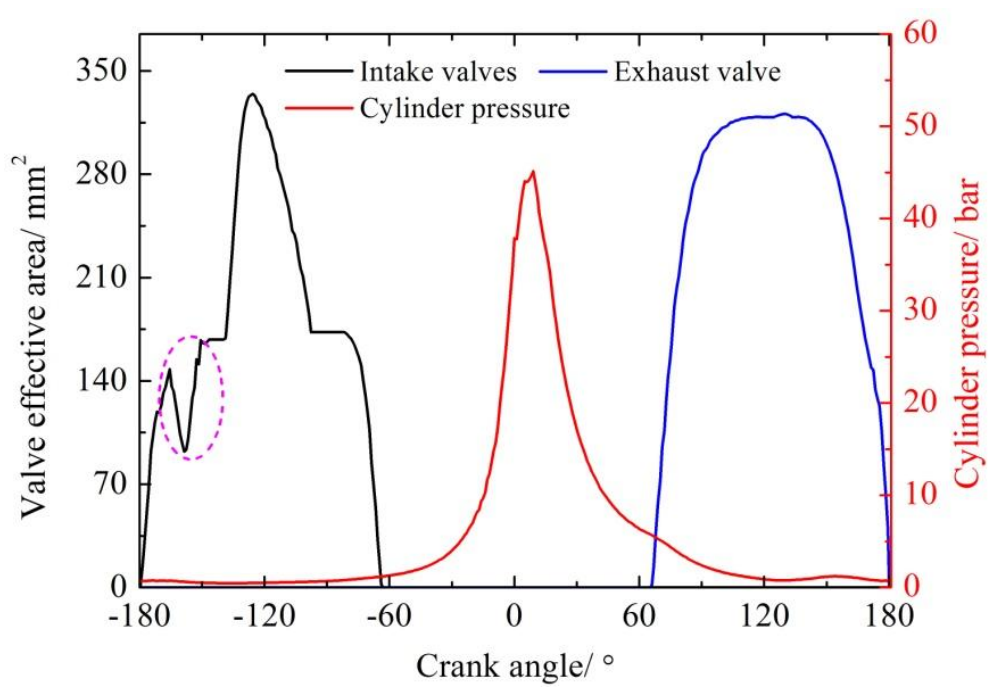

(b) $5000 \mathrm{rpm}, 100 \%$ load

Figure 13 Effective valve opening area and in-cylinder pressure

In order to compare the cylinder combustion characteristics with a reciprocating engine, a four stroke, 4 cylinder reciprocating engine having the same basic engine parameters (compression ratio, stroke and end surface area) was adopted. Figure 14 compares the 1D simulated P-V diagram of the ORP engine and the reciprocating engine at $1000 \mathrm{rpm}$, full load. The intake process was almost identical for the two engines due to the low rotational speed. The difference in the compression stroke mainly happened at the late stage. Evidently, the combustion chamber volume change was greater in the ORP engine close to TDC, which caused a higher fraction of constant volumetric combustion (inferred from the profiles in Figure 10). Based on the P-V diagram, the engine power output per cycle of the ORP engine was higher than the reciprocating engine at $1000 \mathrm{rpm}$ despite of a lower cylinder peak pressure. The power stroke finished round $90^{\circ} \mathrm{CA}$ for the ORP engine; however, it took double time for the reciprocating engine to complete, which caused higher heat losses. Compared with the reciprocating engines, the friction loss of ORP engine per cycle was theoretically lower, which was caused by short cycle period and lower cylinder peak pressure. 


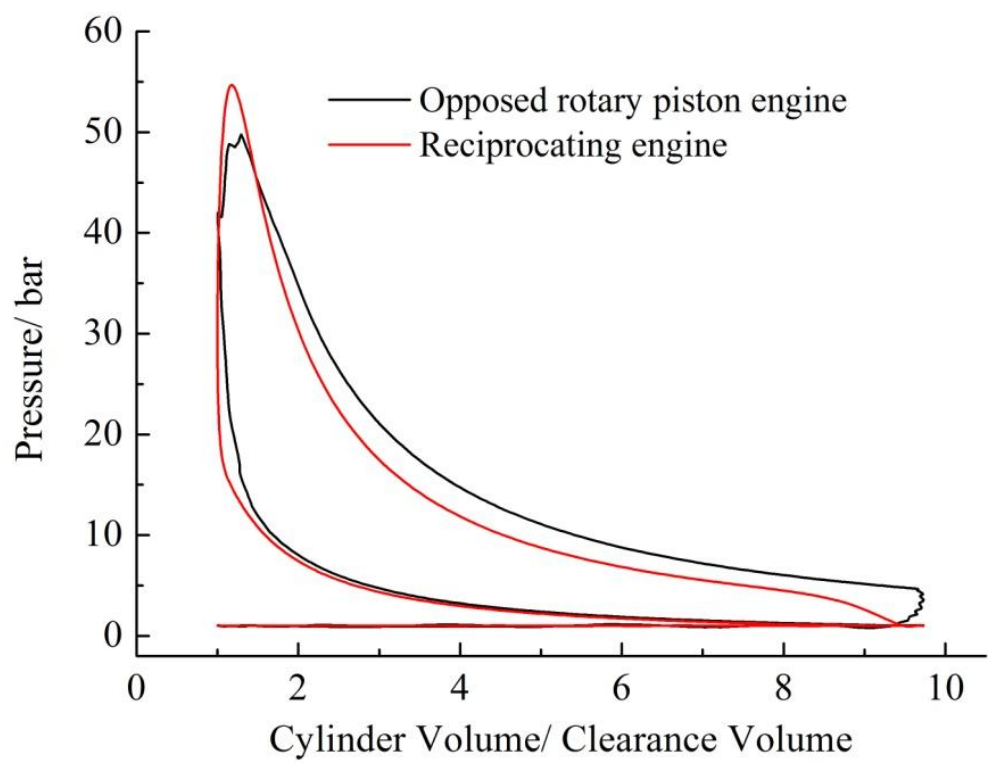

(a) $1000 \mathrm{rpm}, 100 \%$ load

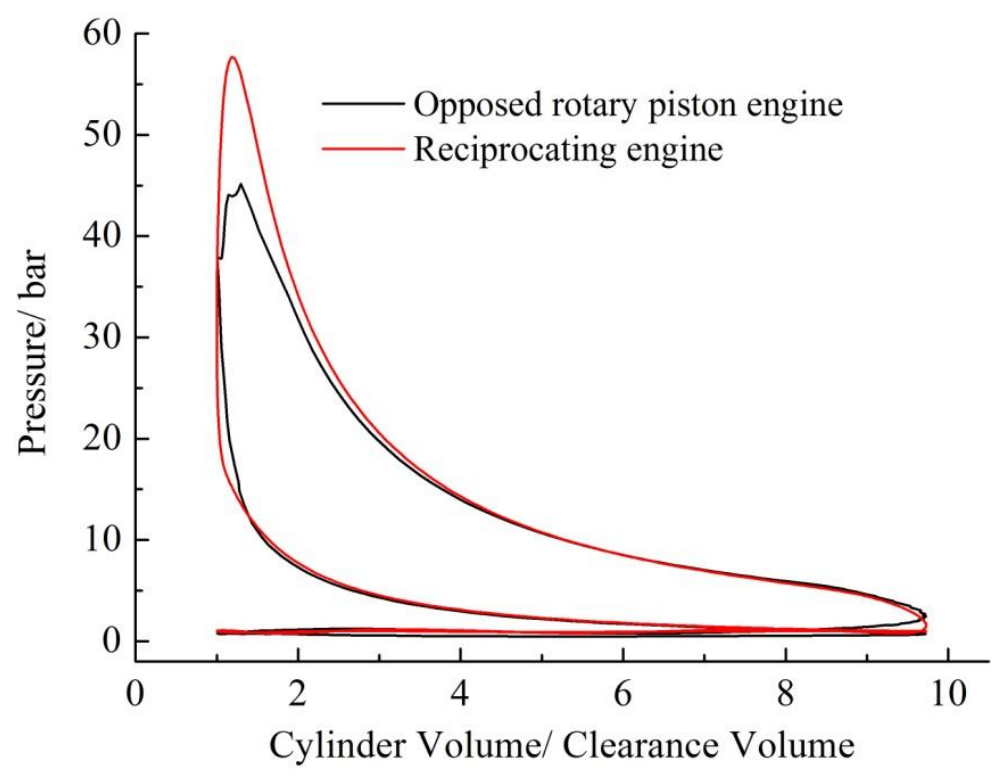

(b) $5000 \mathrm{rpm}, 100 \%$ load

Figure $14 \mathrm{P}-\mathrm{V}$ graphs of the ORP engine and reciprocating engine

The cylinder peak pressure of the reciprocating engine increased at $5000 \mathrm{rpm}$ because of the charging efficiency increase (from 0.9232 to 0.9326 ); however, it decreased for the ORP engine. Except for the combustion process and the early stage of the power stroke, the P-V lines were almost the same for the two engines at $5000 \mathrm{rpm}$. More heat losses and lower fraction of constant volumetric combustion were remedied by a higher cylinder peak pressure for the reciprocating engine. Estimated from the P-V graph, the power density of the ORP engine was much higher than the reciprocating engine, which was a benefit from the short cycle period $\left(360^{\circ} \mathrm{CA}\right)$. However, the short cycle period may lead to higher $\mathrm{CO}$ and unburnt $\mathrm{HC}$ emissions, especially at high engine 
speed conditions. It was also evident that the cylinder peak temperature of the ORP engine was much lower than the reciprocating engine, combined with shorter combustion time, the $\mathrm{NO}_{x}$ emission of the ORP engine was deduced to be lower than reciprocating engines [49]. Power output per cycle would decreased sharply if continue to increase the engine speed, due to lower charging efficiency. Much improvement could be obtained under high engine speed conditions by optimising the valve timing for the ORP engine.

Figures 15 and 16 show the maps of the simulated engine power output, brake specific fuel consumption (BSFC) and brake thermal efficiency. The tendency of the engine torque under full load conditions was different from the conventional reciprocating engines; higher torque at low engine speed was observed for the ORP engine. This was mainly caused by a higher fraction of constant volumetric combustion, less heat losses and short cycle period. The minimum BSFC was observed around $2000 \mathrm{rpm}$ and $100 \%$ load conditions, being lower than $245.0 \mathrm{~g} /(\mathrm{kW} \cdot \mathrm{h})$, which was slightly lower than naturally aspired spark ignition engines [50]. The BSFC could be further decreased by further optimising engine design. The maximum power density was approximately $80 \mathrm{~kW} / \mathrm{L}(0.5468 \mathrm{~L}$ displacement in Figure 15) at $5000 \mathrm{rpm}$. This could be improved if intake valve timing was optimized. The power density will be further elevated if a turbocharger is used, which will benefit from the intake valve structure design. The maximum brake thermal efficiency was approximately $33 \%$ at $2000 \mathrm{rpm}$ and $100 \%$ load conditions. The brake thermal efficiency was higher than the naturally aspired reciprocating engines at low and medium engine speed conditions [51]; however, it was the same level at high speed conditions [52]. These maps provided a preliminary evidence that the ORP engine was a promising alternative to the reciprocating engines applied to the hybrid vehicles and range extenders of hybrid vehicles; also, it had potentials of being the power of the pilotless aircrafts, owning the high power density. These maps could be further extended to lower engine speed due to its stable operation. The application of a lower idle speed could decrease the fuel consumption significantly to meet the $\mathrm{CO}_{2}$ emission target. 


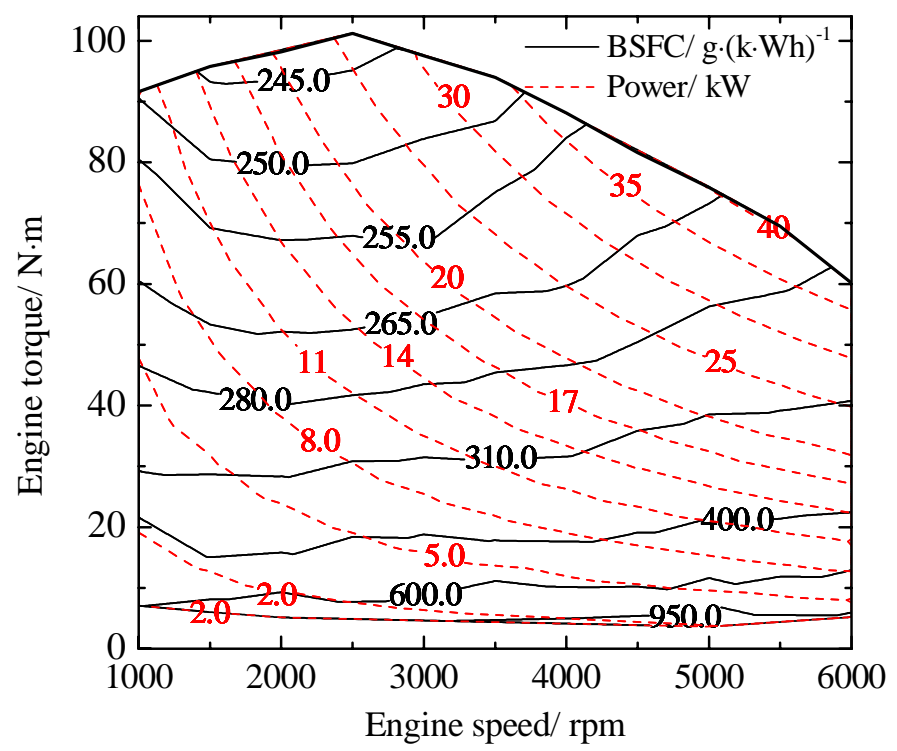

Figure 15 Power output and BSFC maps of the ORP engine: displacement, $0.5468 \mathrm{~L}$.

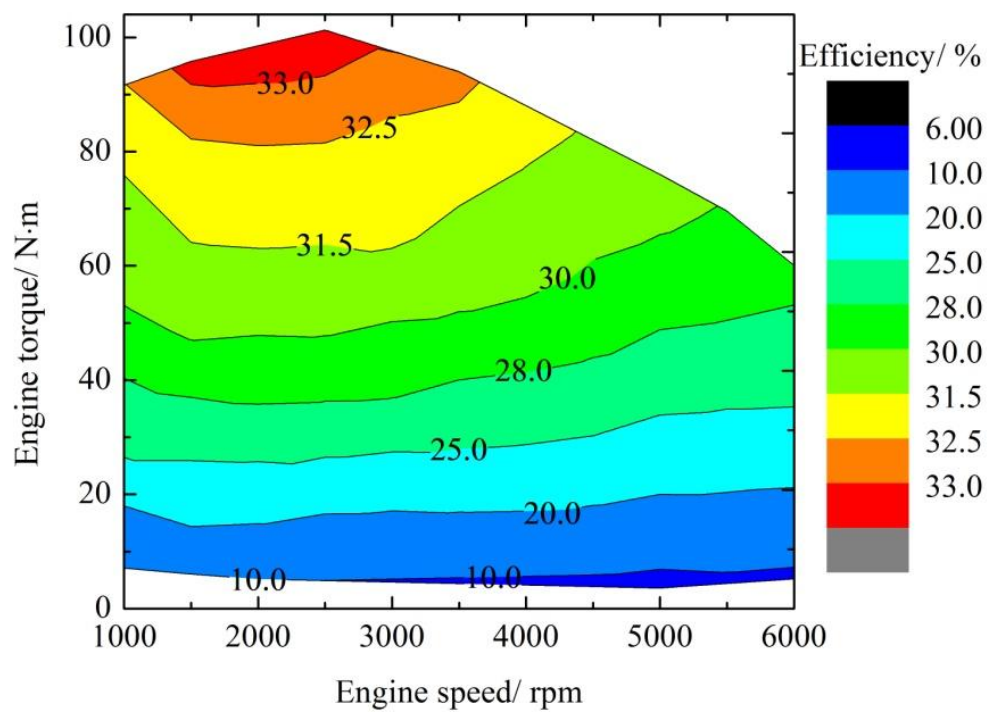

Figure 16 Brake thermal efficiency maps of the ORP engine

\section{Conclusion}

As a promising alternative of the reciprocating engines used in hybrid vehicles and range extenders of hybrid vehicles, the ORP engine is benefited from the higher power density (higher power frequency), lower vibration, lower noise and fewer parts than reciprocating engines. Meanwhile, it avoided the narrow combustion chamber so that higher thermal efficiency and lower emissions could be achieved compared with the Wankel engines. This paper explored the flow pattern in the ORP engine using FLUENT software. Then, the potential merits of the ORP engine were investigated in compared with a reciprocating engine. Further, the engine power output, BSFC and brake thermal efficiency were calculated using WAVE software. The main conclusions were as follows:

(1) At the initial stage of the exhaust stroke, the backflow happened due to the low charging 
efficiency and heat losses. A vortex formed in the exhaust pipe after the port was open. There was not overlap for the intake and exhaust valves; additionally, the fresh charge velocity was low at the beginning of the intake stroke. At the end of the intake stroke, the velocity was still higher than 150 $\mathrm{m} / \mathrm{s}$, which provided the possibility of optimising the intake valve timing to enhance the engine power output.

(2) The geometric angles that the cylinder leading surface covered were $60^{\circ}, 120^{\circ}, 60^{\circ}$ and $120^{\circ}$ in the exhaust stroke, intake stroke, compression stroke and power stroke, respectively. However, they were $120^{\circ}, 60^{\circ}, 120^{\circ}$ and $60^{\circ}$ for the trailing surface. It achieved $120^{\circ}$ geometric angle for each stroke in one cycle, which conduced to increase the charging efficiency. The constant volumetric combustion fraction for the ORP engine was higher than the reciprocating engines at low and medium engine speed, which indicated higher brake thermal efficiency.

(3) The charging efficiency of the ORP engine dropped sharply when the engine speed was higher than $5000 \mathrm{rpm}$. The power density $(\sim 80 \mathrm{~kW} / \mathrm{L})$ of the ORP engine was higher than the reciprocating engines, under the conditions of the same basic geometric parameters. Higher engine power output per cycle was mainly the result of less heat loss and higher constant volumetric combustion fraction under low engine speed. The lowest BSFC of the ORP engine was $\sim 245.0 \mathrm{~g} /(\mathrm{kW} \cdot \mathrm{h})$ around 2000 rpm, $100 \%$ load condition, where the highest brake thermal efficiency was located.

(4) Higher rated power output could be achieved by optimising the valve timing, especially the intake valves. Lower cylinder peak temperature meant less $\mathrm{NO}_{x}$ emissions than reciprocating engines, meanwhile, it had lower $\mathrm{HC}$ and $\mathrm{CO}$ emissions than Wankel engines theoretically as it avoided the narrow and long combustion chambers.

\section{Support Information}

Cylinder pressure distributions at $5000 \mathrm{rpm}$ engine speed. Video S1 shows how the engine works.

\section{Nomenclature:}

BSFC: brake specific fuel consumption

CA: crank angle

Carbon dioxide: $\mathrm{CO}_{2}$

Carbon monoxide: $\mathrm{CO}$

CRE: centric reciprocating engine

Direct injection: DI 
Exhaust gas recirculation: EGR

Friction mean effective pressure: FMEP

Homogeneous charge compression ignition: HCCI

Hydrocarbon: HC

Nitrogen oxides: $\mathrm{NO}_{x}$

ORP: opposed rotary piston

RANS: Reynolds Averaged Naiver-Stoke

Spark ignition: SI

Top dead center: TDC

Variable valve timing: VVT

\section{References}

[1] Amrouche F, Erickson P, Park J, Varnhagen S. Extending the lean operation limit of a gasoline Wankel rotary engine using hydrogen enrichment. IJHE. 2016;41:14261-71.

[2] Gao J, Ma C, Xing S, Sun L, Liu J. Polycyclic aromatic hydrocarbon emissions of non-road diesel engine treated with non-thermal plasma technology. Korean J Chem Eng. 2016;33:3425-33.

[3] Gao J, Tian G, Sorniotti A, Karci AE, Di Palo R. Review of thermal management of catalytic converters to decrease engine emissions during cold start and warm up. Appl Therm Eng. 2019;147:177-87.

[4] Gao J, Chen H, Tian G, Ma C, Zhu F. An analysis of energy flow in a turbocharged diesel engine of a heavy truck and potentials of improving fuel economy and reducing exhaust emissions. Energy Conversion \& Management. 2019;184:456-65.

[5] Wang Q, Jiang B, Li B, Yan Y. A critical review of thermal management models and solutions of lithium-ion batteries for the development of pure electric vehicles. Renewable and Sustainable Energy Reviews. 2016;64:106-28.

[6] Lukic SM, Emadi A. Effects of drivetrain hybridization on fuel economy and dynamic performance of parallel hybrid electric vehicles. ITVT. 2004;53:385-9.

[7] Yong JY, Ramachandaramurthy VK, Tan KM, Mithulananthan N. A review on the state-of-the-art technologies of electric vehicle, its impacts and prospects. Renewable and Sustainable Energy Reviews. 2015;49:365-85.

[8] Ozcanli M, Bas O, Akar MA, Yildizhan S, Serin H. Recent studies on hydrogen usage in Wankel 
SI engine. IJHE. 2018;43:18037-45.

[9] Su T, Ji C, Wang S, Cong X, Shi L. Research on performance of a hydrogen/n-butanol rotary engine at idling and varied excess air ratios. Energy Conversion \& Management. 2018;162:132-8. [10] Fan B, Pan J, Yang W, Chen W, Bani S. The influence of injection strategy on mixture formation and combustion process in a direct injection natural gas rotary engine. ApEn. 2017;187:663-74.

[11] Fan B, Zhang Y, Pan J, Liu Y, Chen W, Otchere P, et al. The influence of hydrogen injection strategy on mixture formation and combustion process in a port injection (PI) rotary engine fueled with natural gas/hydrogen blends. Energy Conversion \& Management. 2018;173:527-38.

[12] Siadkowska K, Wendeker M, Majczak A, Baranski G, Szlachetka M. The influence of some synthetic fuels on the performance and emissions in a wankel engine. SAE Technical Paper; 2014.

[13] $\mathrm{Wu} \mathrm{W}$, Lin Y-R, Chow L. A heat pipe assisted air-cooled rotary wankel engine for improved durability, power and efficiency. SAE Technical Paper; 2014.

[14] Bai S, Tang J, Wang G, Li G. Soot loading estimation model and passive regeneration characteristics of DPF system for heavy-duty engine. Appl Therm Eng. 2016;100:1292-8.

[15] Su T, Ji C, Wang S, Cong X, Shi L, Yang J. Investigation on combustion and emissions characteristics of a hydrogen-blended n-butanol rotary engine. IJHE. 2017;42:26142-51.

[16] Rakopoulos DC, Rakopoulos CD, Giakoumis EG, Dimaratos AM. Characteristics of performance and emissions in high-speed direct injection diesel engine fueled with diethyl ether/diesel fuel blends. Energy. 2012;43:214-24.

[17] Kagawa R, Okazaki S, Somyo N, Akagi Y. A study of a direct-injection stratified-charge rotary engine for motor vehicle application. SAE Transactions. 1993:918-26.

[18] Li L, Tang D, Fan J, Wang X. Simulation of the performance of a direct-injection stratified-charge rotary combustion engine. Hangkong Dongli Xuebao/Journal of Aerospace Power. 2003;18:363-6.

[19] Tashima S, Taqdokoro T, Tadokoro T, Okimoto H, Niwa Y. Development of sequential twin turbo system for rotary engine. SAE transactions. 1991:900-9.

[20] Amrouche F, Erickson P, Park J, Varnhagen S. An experimental investigation of hydrogen-enriched gasoline in a Wankel rotary engine. IJHE. 2014;39:8525-34.

[21] Amrouche F, Erickson P, Park J, Varnhagen S. An experimental evaluation of ultra-lean burn capability of a hydrogen-enriched ethanol-fuelled Wankel engine at full load condition. IJHE. 
2016;41:19231-42.

[22] Fan B, Pan J, Yang W, Zhu Y, Chen W. Effects of hydrogen blending mode on combustion process of a rotary engine fueled with natural gas/hydrogen blends. IJHE. 2016;41:4039-53.

[23] Fan B, Pan J, Yang W, Pan Z, Bani S, Chen W, et al. Combined effect of injection timing and injection angle on mixture formation and combustion process in a direct injection (DI) natural gas rotary engine. Energy. 2017;128:519-30.

[24] Chintala V, Subramanian KA. Assessment of maximum available work of a hydrogen fueled compression ignition engine using exergy analysis. Energy. 2014;67:162-75.

[25] Jithin E, Dinesh K, Mohammad A, Velamati RK. Laminar burning velocity of n-butane/Hydrogen/Air mixtures at elevated temperatures. Energy. 2019;176:410-7.

[26] Fiene J, Braithwaite T, Boehm R, Baghzouz Y, Kell T. Development of a hydrogen engine for a hybrid electric bus. SAE Technical Paper; 2002.

[27] Chintala V, Subramanian K. Experimental investigations on effect of different compression ratios on enhancement of maximum hydrogen energy share in a compression ignition engine under dual-fuel mode. Energy. 2015;87:448-62.

[28] Şöhret Y, Gürbüz H, Akçay İH. Energy and exergy analyses of a hydrogen fueled SI engine: Effect of ignition timing and compression ratio. Energy. 2019;175:410-22.

[29] Serrano J, Jiménez-Espadafor F, López A. Analysis of the effect of the hydrogen as main fuel on the performance of a modified compression ignition engine with water injection. Energy. 2019;173:911-25.

[30] Zhang Y, Zuo Z, Liu J. Numerical analysis on combustion characteristic of leaf spring rotary engine. Energies. 2015;8:8086-109.

[31] Zou T-a, Xu H-j, Pan C-y, Xu X-j, Chen H. Mathematical modeling and analysis of thermodynamic processes in a twin-rotor piston engine. Journal of Central South University. 2014;21:4163-71.

[32] Deng H, Pan C-y, Wang X-c, Zhang L, Deng L. Comparison of two types of twin-rotor piston engine mechanisms. Journal of Central South University. 2013;20:363-71.

[33] Chen H, Pan C-y, Xu H-j, Deng H, Han C. Analysis on structural characteristics of rotors in twin-rotor cylinder-embedded piston engine. Journal of Central South University. 2014;21:2240-52. [34] Huang Z, Wang J, Liu B, Zeng K, Yu J, Jiang D. Combustion characteristics of a direct-injection engine fueled with natural gas-hydrogen blends under different ignition timings. 
Fuel. 2007;86:381-7.

[35] Zhang L, Xu H-j, Pan C-y, Xu X-j. Combustion simulation and key parameter optimization for opposite axial piston engine in small-scale. Journal of Central South University. 2015;22:3397-408. [36] Liu C-M, You J-J, Sung C-K, Huang C-YJE. Modified intake and exhaust system for piston-type compressed air engines. Energy. 2015;90:516-24.

[37] Pan J, Chen W, Yang W, Xiao M, Zhu Y, Fan BJEP, et al. Effects of intake and exhaust valve timing on the performance of an air-powered rotary engine. Sustainable Energy. 2018;37:1462-74.

[38] https://www.otechos.com.

[39] Gong C, Li Z, Chen Y, Liu J, Liu F, Han Y. Influence of ignition timing on combustion and emissions of a spark-ignition methanol engine with added hydrogen under lean-burn conditions. Fuel. 2019;235:227-38.

[40] Wei M, Song P, Zhao B, Shi L, Wang Z, Ma C. Unsteady flow in the suction process of a scroll expander for an ORC waste heat recovery system. Appl Therm Eng. 2015;78:460-70.

[41] Ceviz M, Akın M. Design of a new SI engine intake manifold with variable length plenum. Energy Conversion \& Management. 2010;51:2239-44.

[42] Sandquist H, Wallesten J, Enwald K, Strömberg S. Influence of valve overlap strategies on residual gas fraction and combustion in a spark-ignition engine at idle. SAE Technical Paper; 1997.

[43] Ishibashi Y, Asai M. Improving the exhaust emissions of two-stroke engines by applying the activated radical combustion. SAE Technical Paper; 1996.

[44] Ganesan V. Internal combustion engines: McGraw Hill Education (India) Pvt Ltd; 2012.

[45] Chang J, Kim M, Min K. Detection of misfire and knock in spark ignition engines by wavelet transform of engine block vibration signals. MeScT. 2002;13:1108-14.

[46] Hoekstra RL, Van Blarigan P, Mulligan N. NOx emissions and efficiency of hydrogen, natural gas, and hydrogen/natural gas blended fuels. SAE Technical Paper; 1996.

[47] Potul S, Nachnolkar R, Bhave S. Analysis of change in intake manifold length and development of variable intake system. International journal of scientific \& technology research. 2014;3:223-8.

[48] Sher E, Bar-Kohany T. Optimization of variable valve timing for maximizing performance of an unthrottled SI engine-a theoretical study. Energy. 2002;27:757-75.

[49] Williams A, Pourkashanian M, Jones J, Rowlands L. A review of NOx formation and reduction mechanisms in combustion systems, with particular reference to coal. Journal of the Institute of 
Energy. 1997;70:102-13.

[50] Pourkhesalian AM, Shamekhi AH, Salimi F. Alternative fuel and gasoline in an SI engine: A comparative study of performance and emissions characteristics. Fuel. 2010;89:1056-63.

[51] Arpa O, Yumrutas R. Experimental investigation of gasoline-like fuel obtained from waste lubrication oil on engine performance and exhaust emission. Fuel Process Technol. 2010;91:197-204.

[52] Gharehghani A, Hosseini R, Mirsalim M, Yusaf TF. A comparative study on the first and second law analysis and performance characteristics of a spark ignition engine using either natural gas or gasoline. Fuel. 2015;158:488-93. 